Portland State University

PDXScholar

9-7-1993

\title{
The Identity in Crisis: A New Approach to the Culture Shock Experience of University Exchange Students
}

Christina Maria Luther

Portland State University

Follow this and additional works at: https://pdxscholar.library.pdx.edu/open_access_etds

Part of the Bilingual, Multilingual, and Multicultural Education Commons, and the First and Second Language Acquisition Commons

Let us know how access to this document benefits you.

\section{Recommended Citation}

Luther, Christina Maria, "The Identity in Crisis: A New Approach to the Culture Shock Experience of University Exchange Students" (1993). Dissertations and Theses. Paper 4615.

https://doi.org/10.15760/etd.6499

This Thesis is brought to you for free and open access. It has been accepted for inclusion in Dissertations and Theses by an authorized administrator of PDXScholar. Please contact us if we can make this document more accessible: pdxscholar@pdx.edu. 
AN ABSTRACT OF THE THESIS OF Christina Maria Luther for the Master of Arts in TESOL presented September 7, 1993.

Title: The Identity in Crisis: A New Approach to the Culture Shock Experience of University Exchange Students.

APPROVED BY THE MEMBERS OF THE THESIS COMMITTEE:

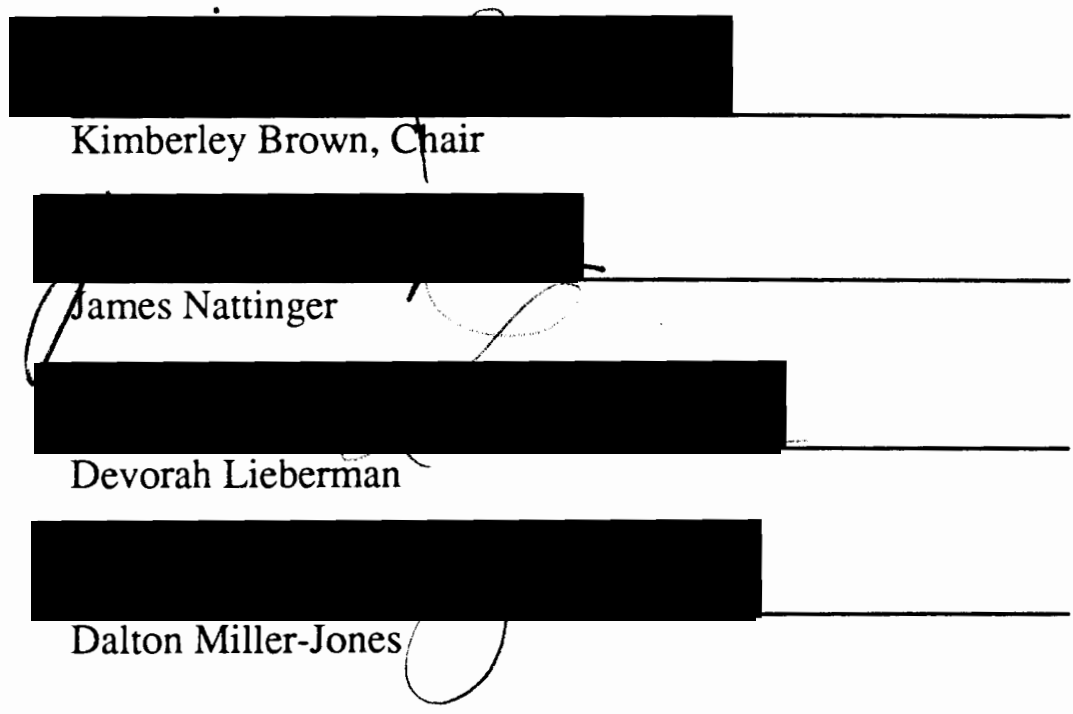

The relationship of language and culture is explored in this thesis for the purpose of better understanding why all sojourners, regardless of preparation, experience some degree of culture shock. The author begins with a review of literature on culture shock establishing that the native language of sojourners is not considered to be of any consequence to the sojourning experience. The fields of intercultural communication, social psychology and psychology are then explored to establish the link between language and culture and to introduce the notion of linguistic identity. Evidence found in 
each of these fields leads the author to conclude that linguistic identity must become a focal point of language instruction and that both language and linguistic identity must be addressed more effectively in pre-departure orientations. Also included is a research proposal which is designed to test pre-departure orientation strategies which introduce students to linguistic identity and to track their transition experiences over the course of a year-long study abroad sojourn. 
THE IDENTITY IN CRISIS: A NEW APPROACH TO THE CULTURE SHOCK EXPERIENCE OF UNIVERSITY EXCHANGE STUDENTS

by

CHRISTINA MARIA LUTHER

A thesis submitted in partial fulfillment of the requirements for the degree of

MASTER OF ARTS

in

TESOL

Portland State University

1993 


\section{TO THE OFFICE OF GRADUATE STUDIES:}

The members of the Committee approve the thesis of Christina Maria Luther presented September 7, 1993.

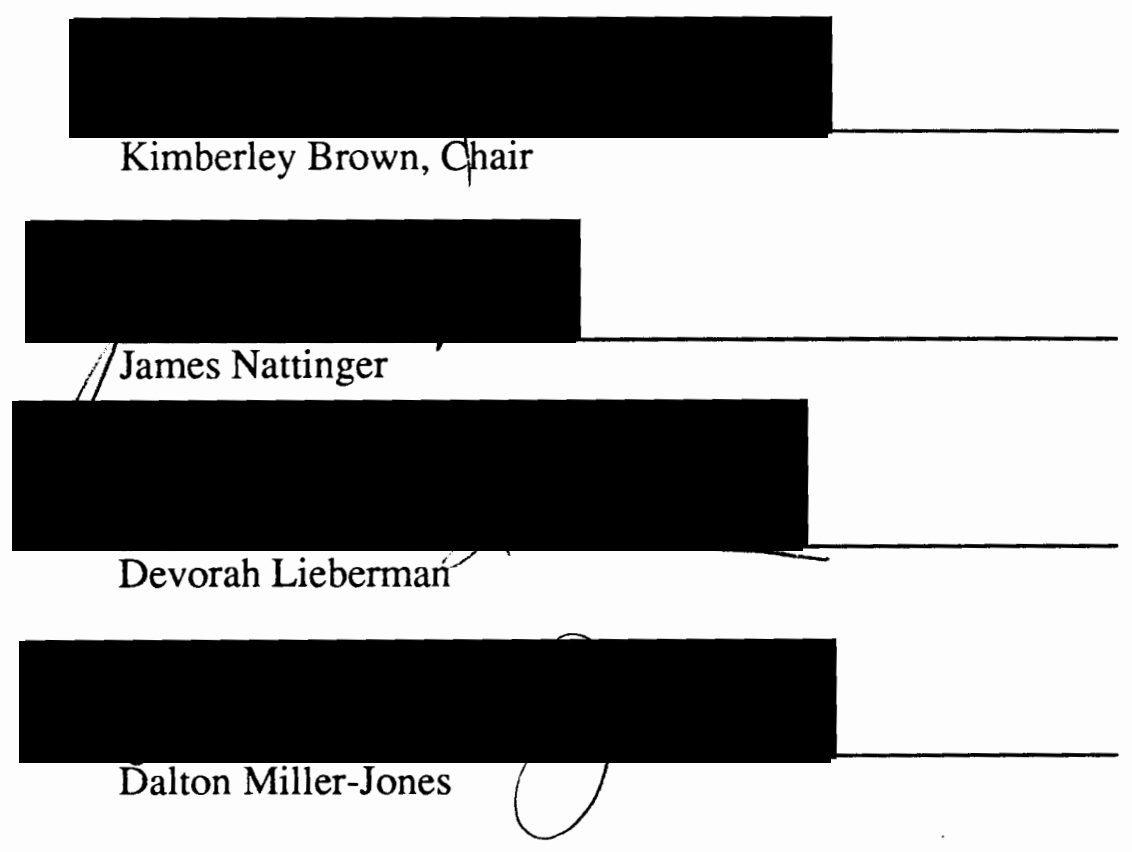

APPROVED:

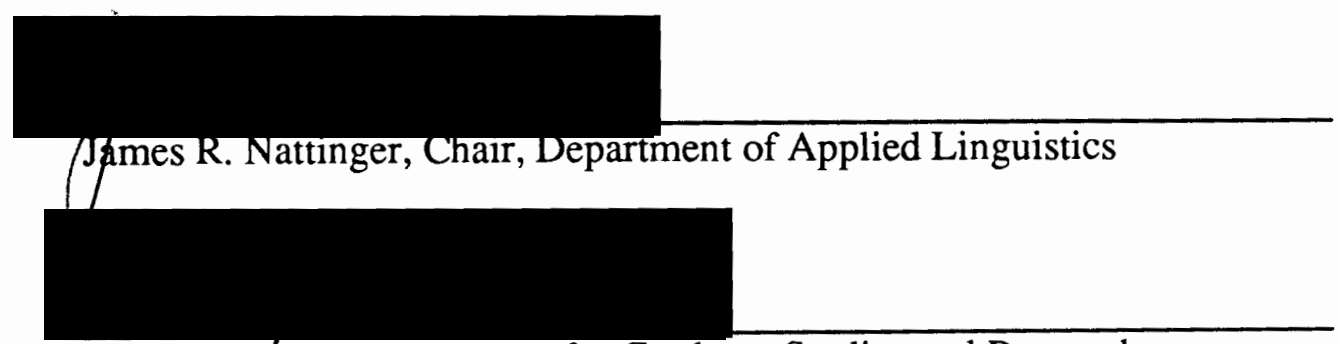

Roy W. Kфch, Vice Provost for Graduate Studies and Research 
TABLE OF CONTENTS

PAGE

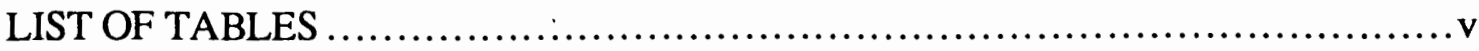

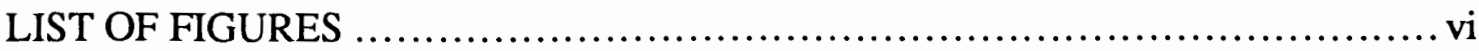

PREFACE .......................................................................... vii

CHAPTER

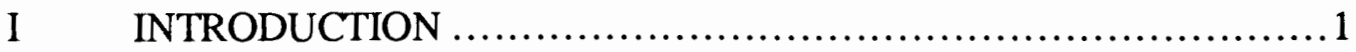

Research Questions ......................................4

Definition of Terms ...................................... 7

II CULTURE SHOCK - THE EXISTING PARADIGM:

A REVIEW OF THE LITERATURE ............................. 13

III IN SEARCH OF EXPLANATIONS: A FORAY INTO

FOUR AREAS OF INTEREST ................................... 30

Alexander Guiora............................................. 32

Intercultural Communication............................... 36

Social Psychology .......................................... 45

Identity Crisis.......................................... 54

IV LINGUISTIC IDENTITY: INTEGRATING LANGUAGE INTO THE CULTURE SHOCK PARADIGM ..................... 62

$\mathrm{V}$ TOWARDS THE DEMYSTIFICATION OF CULTURE SHOCK...... 73

Review................................................. 74

Implications of this Research ............................. 80

Project for Further Research ............................. 87

REFERENCES ........................................................ 90 


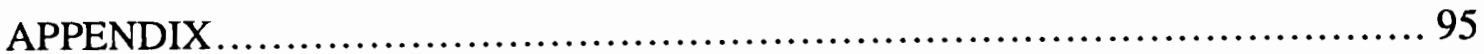




\section{LIST OF TABLES}

TABLE

PAGE

I. Stages of culture shock.................................................... 20

II. Comparison of identity crisis and culture shock symptoms ............... 59 


\section{LIST OF FIGURES}

FIGURE

PAGE

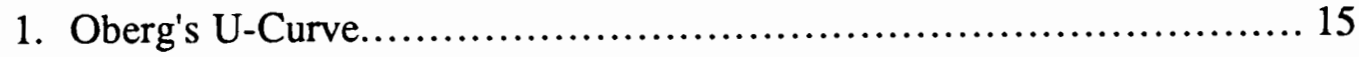

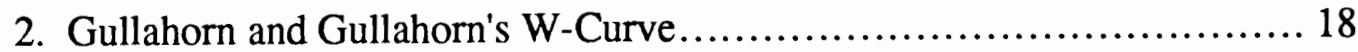




\section{PREFACE}

Michelle finally got home around eleven o'clock and came to my room without even checking her door to find my message. It felt like I had been waiting the entire long and particularly difficult day for a chance to TALK. Not that I hadn't been talking all day, I certainly had been, but there was something different about those evenings when she and I got together for what were regular gripe sessions. I don't know when we had the first one, but they had definitely become a habit. We would reach a point when we could no longer stand to speak in German or to try to "be" German and had to get together to speak English as fast and as sloppily as we possibly could. When we finally got together, we never wasted any time. Tonight was the same.

Even as she was putting water on to boil for tea, Michelle began voicing her frustration with how her day had gone. That was the other remarkable thing - neither one of us was ever NOT ready for a gripe session! "Today I was playing soccer with the team from The Joker and I kept cracking jokes. NOBODY laughed. Or if they did laugh, it seemed like they did only because they felt like they should, not because they thought what I said was funny. Can you believe it, a couple of times someone actually corrected me when I was trying to make a joke! They assume that because my German is so bad I couldn't possibly be purposefully making a joke. Idiots." I sympathized with her. Despite the fact that I had been studying German for ten years, eight years longer than Michelle, and despite the fact that even my language instructor mistook me for a native when he first met me, no one took my jokes seriously. Everyone assumed I had made a grammatical error or was not sure of the proper syntax. Sometimes they corrected me patiently, other times they just pretended I had said nothing out of the ordinary. 
Communicating humor was only part of the problem, but it was a big part of the problem. Michelle and I are both beginning to realize how big a role humor plays in our lives and that without it we feel quite stodgy. Todd joined us about midnight. He had just returned from a friend's house and came up when he saw Michelle's light on. He grabbed a cup and lost no time in joining our session. "Have you guys ever noticed how weird you sometimes sound to yourself when you speak German?" Michelle knew exactly what he was talking about. I hedged, but both of them came at me with what seemed like hundreds of scenarios which clearly illustrated their point. "Are you kidding, Christina? You are either always trying to show off your superior language skills, or you get so lost in your German sentences that you have to make them five times as complicated to get out of them!" I still didn't really get it. Then I started thinking about the way I had talked with my colleagues at the School of Business earlier that day. It was true. I did formulate much more complex sentences in casual German conversation than I ever would in English conversation. And I thought about Christoph. He had been such a clown when he was in Portland studying, but when I met him in Freiburg he was much more serious. Until he began speaking English again. Then the clown returned. It was not that he was more superficial when he spoke in English, just different. And what about Xavier? The first time I saw him speak French for an extended period of time I hardly recognized him. I didn't understand anything, but the way he moved, the way his gestures changed, his intonation... he was like a different person. 


\section{CHAPTER I}

I must bring a voice of my own. I must enter the dialogue on my own authority knowing that other voices have enabled mine, but no longer can I subordinate mine to theirs. (Sommers, 1992, p. 29)

It seems curious that in the literature on culture shock, language is mentioned only in a peripheral way. The difficulties one has communicating in a foreign culture are considered obvious. Of course it will be hard to cope in a different culture where people speak languages other than those we speak. Also considered a given is the probability that if one has even a rudimentary knowledge of the language of the host culture the experience of that culture will be smoother. Of course it will be easier to adjust to living in a new culture if one is able to speak some of the language. In fact, one will probably have very few problems adjusting to a new culture if one has a good command of the language spoken by the people who live in it. But this is not always the case, and those students who enter a new culture with two or three years of language study behind them may be very surprised to find that they still have troubles.

It is frequently argued that the problems students, in fact sojourners in general, face have to do with cultural differences. Indeed the differences most often commented on are such things as odd foods, smells, curious ways of doing daily chores such as shopping or banking, peculiar daily schedules involving siestas or the like. Supposedly these changes in familiar routine are traumatic enough as to render the sojourner hostile, aggressive, (Oberg, 1960) even the victim of a mental illness (Foster, 1971). The strength of these terms is extreme for what most people experience, though, and with preparation the sojourner should be able to cope with these differences. Yet even the most prepared sojourners experience culture shock. 
I think the reasons for culture shock lie much deeper than such, however important, superficial differences as food, smells and daily routines. My own most vivid memory of culture shock did not involve food or smells, nor did it involve cultural peculiarities such as having to shop by 1:00 pm on Saturday or go hungry until Monday morning. My memory of culture shock was the constant nagging thought that people were not getting to know me. Although I spoke good German, in fact was mistaken for a native on many occasions, I felt that I was not communicating my SELF to people effectively. I felt that my new friends were missing the nuances of who I was and that no matter how hard I tried, I was not going to be very successful at revealing that person to them.

Upon confiding my frustrations to a friend, I was surprised to find out that she shared my feelings. In fact, many of the students who were participating in the exchange program with us were experiencing the same frustrations. We had read about culture shock, and knew that we could expect to feel frustrated after the first two or three months passed and we began to settle into our new lives, but we hadn't been told and we hadn't read anywhere that the frustrations we would feel would be so deeply rooted. We hadn't anticipated the possibility that the experience of culture shock might cause some of us to question much of what we had, until that trip abroad, taken for granted, including our confidence in who we felt we were.

If I had been surprised to find that some of the exchange students shared my frustrations, then my surprise was even greater when I began speaking to people at home who had participated in similar year-long exchange programs. Even after being home for a few years these people remembered feeling the same frustrations. I began asking people specifically how they would describe their experience of culture shock. Again and again I heard I couldn't make people know who I really am. I met people and made friends, but I always felt like I was playing a part in a play. I was familiar with the role, 
but it was not ME. I often wondered what my friends abroad would think of me if they saw me at home! We all experienced a slow period of realization that the ME who we were abroad was not the ME who we were at home. There was some apprehension that these two ME's might not be reconcilable. This possibility that I had actually developed a second personality was most disturbing. Not to mention inconvenient - how peculiar it would be if I found that I had to switch back and forth between the foreign ME and the native ME! How would I know when to be whom?

When I first encountered Guiora's "language ego" (1972) the pieces of this peculiar puzzle began to fall into place. This language ego provided an important clue to what might be at the heart of the experience of culture shock I had shared with other exchange students. Perhaps the feeling we shared that we were becoming different persons in our chosen second cultures could be accounted for if we acknowledged that our identities were formed through the languages we spoke natively. If people develop identities in relation to their first languages, would they not also develop identities in relation to second, or to subsequent, languages?

I mentioned at the beginning of this paper that language is only mentioned peripherally in discussions of culture shock. I believe, though, that the native language of an individual plays a peculiar role in the individual's experience of a second culture. It is through this language that we learn about the environment into which we are born. And it is language that shapes our impression of the world which surrounds us. Language permits us to classify people according to social group and we do so instantaneously. Language is also used to identify ourselves with a social group. With language we draw ourselves into preferred groups and shun those groups with whom we do not want to be associated (Nattinger, 1993).

By exploring the following questions in this thesis, I will suggest that a different approach needs to be taken for preparing individuals for that aspect of the sojourning 
experience known as culture shock. This approach must take into consideration two components which have been insufficiently addressed in culture shock literature: language and linguistic identity. The review of culture shock literature presented in Chapter II underscores the lack of attention paid to these two components. While there has been significant evolution in our understanding of culture shock in the last thirty years, there has not been a great deal of deviation from the original path laid by Oberg, consequently the exploration has fallen short of the necessary depth. Research since 1960 has been devoted more to outlining the symptoms of culture shock than to seeking to understand why culture shock occurs and what can be done to prepare sojourners for it.

In Chapter III, an interdisciplinary exploration is presented into three areas of interest related to culture shock: speech communication, social psychology and psychology. This foray is designed to point out where culture shock research is lacking and how central language and individual differences are to the culture shock experience. Their incorporation into the culture shock model will provide a stronger basis upon which sojourners might prepare for their excursions abroad.

\section{RESEARCH QUESTIONS}

There are a number of questions which I will address in my exploration of the role of language in the experience of culture shock. The most guiding question is why do sojourners feel their hosts do not get to know them despite the fact that they have contact with natives and can speak the host language to such a degree as to make their basic needs understood? This question stems from my own experiences as well as those of other people who felt that they were never completely successful in being themselves abroad.

The second question which has guided my research concerns the role of language in the experience of culture shock. Traditionally language is given only superficial 
mention in the literature on culture shock. Where language is mentioned, the focus is exclusively on the language of the host culture. Guidebooks encourage the traveler to learn a few key phrases and academic exchange programs frequently require a minimum of two years of college level instruction in the language of the host country, but beyond these recommendations little attention is paid to language. The native language of the sojourner is given no mention at all. I wonder though if language, specifically that native language, plays a greater role in the experience of culture shock than it is given credit for, and if so what the nature of that relationship is. Let us presuppose that language is related to culture shock. What then, is the relationship of language to culture?

- Is the relationship between language and culture shock superficial?

I can't speak like they do so I can't get along here? If this is the case, then the native language really plays no role at all and as soon as sojourners become proficient in the language of the host culture their experience of culture shock will diminish.

- Does the relationship between language and culture shock lie deeper than proficiency?

My language is such an integral part of me that when I am forced to rely on another language I don't feel like me. If this is the case, then sojourners' proficiency in the language of their hosts, while important, is not so crucially linked to their experience of culture shock, rather it is their native languages which provide that crucial link. In order to adequately answer these questions, I must digress into the field of psychology to answer the following questions:

- What role does language play in the development of the self?

- Is it possible that individuals develop new selves when they learn a new language?

- What role does this new self play in the culture shock experience?

I feel compelled to note that within the scope of a master's thesis it will be impossible to conduct the studies, interviews and research necessary to come up with conclusive 
answers to these questions. Instead, I intend to present an exploration of the topics raised in each of the questions. A strong interdisciplinary framework must be laid out in order to understand the significance of the role language plays in the culture shock experience. From many different vantage points, this thesis focuses on language and on linguistic identity so that further empirical research done in this area can shift focus to these areas as well.

It is also important to clarify what I mean when I write of sojourners being able to speak a language because communicative competence is far more complex than simply knowing how to say words in another language. There are four basic components of communicative competence: strategic competence, sociolinguistic competence, pragmatic competence, and discourse competence. Different researchers (Bachman, 1990; Brown, 1987; Canale, 1983; Richard \& Rodgers, 1986) rank the components in varying orders and combine them under varying rubrics in their discussions, but in the interest of the reader I will confine myself to a description of each of the four competencies, providing a basic understanding of how they fit together to create the complex picture of communicative competence.

Bachman (1990) discusses communicative competence as being "an expanded conception of language proficiency whose distinguishing characteristic is its recognition of the importance of context beyond the sentence to the appropriate use of language" ( $p$. 82). Strategic competence combines our knowledge of a language with an ability to evaluate context and decide how best to communicate the desired message. It is the ability to employ verbal and nonverbal coping strategies "to compensate for breakdowns in communication due to insufficient competence or to performance limitations" (Canale, 1983, p. 339).

Closely tied to the evaluation of context are sociolinguistic and pragmatic competence. Sociolinguistic competence is concerned primarily with understanding of 
context. Bachman describes it as "the sensitivity to, or control of, the conventions of language use that are determined by the features of the specific language use in context" (p. 94). Interlocutors must take into consideration such nuances of speech as dialect, variety and register then decide what it is they may, and may not, use in a given situation.

Pragmatic competence has to do with the ability to decide what is appropriate and/or possible within a given context. This type of competence "is concerned with the relationships between utterances and the acts or functions that speakers (or writers) intend to perform through these utterances... and the characteristics of the context of language use that determine the appropriateness of utterances" (pp. 89-90).

The final type of competence is discourse competence which has to do with the "interpretation of individual message elements in terms of their interconnectedness and of how meaning is represented in relationship to the entire discourse or text" (Richards and Rodgers, 1986, p. 71). The speaker must be able to determine how the parts of a discourse fit together and what that pattern of connectedness means for the conversation.

It was once believed that if an individual was competent in the four skill areas, reading, writing, speaking, and hearing, then that individual was competent in the language. This is clearly no longer the case. There is a myriad of nuance and subtlety to speaking a language. The reader should hold these notions in mind while reading. The ability to use language is an extremely complex task and the mastery of it is one not to be taken lightly for it will open new worlds to the accomplished speaker.

\section{DEFINITION OF TERMS}

The reader may find the choice of the word self in my discussion to be awkward; therefore, I would like to explain my reasons for choosing it. As I began this research, my questions were formed around the notion of personality. In my own experience as a sojourner in Germany, I found that I was a more serious person in German, that my voice 
deepened, and that I formed more complicated sentences in casual speech than I would have in my native language. People who know me in both languages/cultures tell me that I have a very different personality in German than I do in English, so personality was the obvious choice. A psychology professor questioned my choice though, pointing out that within the field of psychology the term had become very loaded. Scientific terminology inevitably flows into the vernacular where all sorts of exaggerated meanings are attached. Therefore it was recommended that I find a word which would not conjure up images in the minds of my readers which might cloud what I want them to read. I considered using the term ego but discarded it for two reasons. First of all, its meaning has been even more confounded in vernacular use than my initial choice. Secondly, I decided that it is important to keep my own ideas distinct from those of Alexander Guiora whose construct, the language ego, plays a central role in my discussion. Guiora uses the term personality in his articles, so occasionally it will creep into my discussion. Researchers in the field of social psychology discuss social identity which will also occasionally appear in my paper. But the term I have chosen to use, self, is not used too often by cited researchers so by using it I will keep my own ideas more clearly separate from those of other researchers.

It is also important to clarify the meaning of communication as it is used in this paper since the use may be considered limited. Communication is a word which is used frequently by the media and may have come to be understood too easily. A crucial aspect of this phenomenon which is too often overlooked or taken for granted, but is integral to the argument of this paper, is that for communication to be successful, the speaker's intended message must be understood by the recipient of the message as it was intended (Green, 1989). As Green (1989) points out, "many use the term communicate interchangeably with speak or write [original italics]" (p. 1). This is only half of the picture. Green goes on to say that "the term communication presupposes achievement of 
the intended effect of verbal action upon the addressee, whereas speaking and writing do not" (p. 1). The achievement of this task is particularly difficult in the realm of intercultural communication where different languages and styles of intercourse impede the successful transfer of messages. It is imperative that the reader recall this definition of communication while perusing this paper.

It is necessary that I supply the reader with an explanation of the subject group intended in this research so as to avoid unnecessary generalization. The research I have done in the field of psychology has indicated that I cannot pretend to extend my notions of identity and identity crisis beyond the scope of the western world. The notions I will write about in this thesis are limited to the northwestern world, including the United States, Canada and Northern Europe. The notions of self in the eastern world, as well as in the Latin world, differ too greatly to make an attempt at clustering them together acceptable.

Related to the definition of subject group is a necessary definition of what sort of travellers I refer to with the word sojourner. I have chosen this word to distinguish this particular type of traveller from tourists and migrants because the experiences of each of the three types are significantly different. Sojourners are those travellers who spend what Furnham (1988) calls a medium length of time, six months to five years, in their host country. They do not intend to settle in this new country, as migrants do, rather they intend to return to their homes. Sojourners also differ from tourists and migrants in that their motives for venturing abroad are "specific and goal-oriented" (Furnham, 1988, p. 337). Tourists' motives, as well as those of migrants, are defined by Furnham (1988) as being vague and complex.

Finally, since this paper has been written in partial fulfillment of an academic degree and therefore has been prepared within an academic framework, it is necessary to explain the untraditional, indeed unacademic, choice of voice that I have made. The 
questions I raise in this thesis stem from personal experience. As I have discussed in this chapter, they arose during a year of study in Germany and have stayed with me. The ideas I explore have been inevitably regarded with my own past, and potential, sojourning experiences always in mind. As I began to write, it quickly became clear that the traditional form seemed very artificial since the ideas about which I was writing were so close to me. I was, and am, a participant-observer of culture shock.

The problem I faced in deciding on an appropriate, and satisfactory, tone is similar to one discussed by Geertz (1988) of "how to get an I-witnessing author into a they-picturing story" (p. 84). Geertz writes about the struggle of ethnographic researchers who immerse themselves in the cultures they observe for the express purpose of gaining the insight of an insider, yet must, in their reports, maintain the objective tone of the anthropological scientist. The traditional form scientific researchers and academicians adhere to requires the use of an impersonal third person pronoun which, in order to avoid gender bias, must appear in the plural form - they. Although the reasons behind the ethnographic paradox appear to be quite different from my own paradox, I have actually immersed myself in a foreign topic for the purpose of observation; the problem of voice I have encountered is similar to the problem anthropologists face.

This thesis breaks ground on a number of levels. On the level of research I suggest that, until now, an important idea has been completely overlooked by the researchers of culture shock. On the academic level, I suggest that a philosophical exploration is a viable option for Master's thesis work, even in the area of Applied Linguistics. Finally, at the personal level, I suggest that an important voice, that of the student, may be unnecessarily suppressed by the academic form. While it is inevitable that writers' voices be heard in their work, there is no reason why students should not be allowed, even within an academic framework, to acknowledge their voices in appropriate situations with the use of "I". 
Sommers (1992) advocates encouraging students to use their own voices. She writes of people who cannot trust their own voices, who get lost in their sources so much that they forget about what their own ideas are. Geisler (1992) underscores Sommers' argument, stating that writers are often not taken seriously or their arguments are not considered valid when they do not cloak their findings in the mantle of academic writing. Unfortunately, the tradition demands that writers either write personal essays or academic essays. No real middle ground has existed. But that tradition is changing (Geertz, 1988; Geisler, 1992; Sommers, 1992). "These either/or ways of seeing things", according to Sommers (1992) "exclude life and real revision by pushing us to safe positions, to what is known. They are safe positions that exclude each other and don't allow for any ambiguity, uncertainty" (p. 29). Yet, she writes, only when suspended "between either and or can [one] move away from conventional boundaries and begin to see shapes and shadows and contours - ambiguity, uncertainty" (p. 29). Although Sommers writes from the position of an established academician, someone who has earned the right to express herself, her argument is for encouraging students to become comfortable with expressing themselves apart from the academic form. Indeed she argues that such personal writing should be accepted by academia as an equally valid form of writing as the traditional form. Geertz (1988) supports this recommendation, insisting on "rendering your account credible through rendering your person so" (p. 79). The greatest danger Sommers foresees in opening up the world of academic writing to incorporate personal writing is that "the uncontrollable world of ambiguity and uncertainty opens up" (p. 30). This is an exciting prospect.

As is stated in the quote which appears at the head of this chapter, I acknowledge that other voices have enabled mine, and I give them credit in the third chapter, "but no longer can I subordinate mine to theirs" (Sommers, 1992, p. 29). The essays I have read on academic writing (Clark \& Wiedenhaupt, 1992; Geisler, 1992; Sommers, 1992) 
encourage changing the traditional academic form to incorporate personal voice. A similar change is also occurring in the field of anthropology, especially in participant/observer studies (Geertz, 1988). Since this thesis is a quasiparticipant/observer research project, and since I believe that the change the academic tradition is undergoing is viable, it is appropriate that I write in the voice which is satisfactory to me. 


\title{
CHAPTER II
}

\section{CULTURE SHOCK - THE EXISTING PARADIGM: A REVIEW OF THE LITERATURE}

\begin{abstract}
Most of culture lies hidden and is outside voluntary control, making up the warp and weft of human existence. It penetrates to the root of [an individual's] nervous system and determines how he perceives the world. Even when small fragments of culture are elevated to awareness, they are difficult to change. (Hall, 1969, p.188)
\end{abstract}

No discussion of culture shock would be complete without reference to Oberg, who is credited with coining the term in a 1960 article. His initial empirical definition of culture shock still referred to today and has been the basis of extensive research. While it is impossible to provide a conclusive review of that research here, the overview provided will give the reader a solid understanding of the evolutionary process the term has undergone. Since its inception in 1960, culture shock has been described as a medical ailment (Oberg, 1960) which, if the proper steps are followed, is curable. It has been referred to as a profound psychological ailment (Foster, 1971) which could range in intensity from mild disorientation to "such severe disorders as psychosis, alcoholism, and even suicide" (Weaver, 1986, p. 111). The focus of these early discussions was on trauma and disruption, but as the reader will see from the following overview, culture shock is being viewed today in a radically different light. As early as 1972 , Adler acknowledged the possibility that an experience like culture shock might provide an opportunity for development. Later, Adler (1977) stressed the importance of such experiences in a world which is increasingly international in scope. A more recent work cited is Weaver's (1986). He brings back to the discussion the psychological, but with a refreshing focus on the benefits of what he calls an identity crisis. 
Because culture shock is an experience of the individual, it cannot be wrapped in the neat package of a definition which can be applied to every individual's encounter. But because it is something from which every sojourner suffers to some degree, attempts are made again and again to define it. The first such attempt was made by Oberg (1960). The ideas expressed in his article comprise an intricate description of what happens when one goes abroad for an extended period of time. It is not my intention to discredit Oberg's definition for it provided a crucial framework within which research into the notion of culture shock became possible. Despite the fact that his description focuses on the tangible and observable, it represents the vital first step on what is proving to be an arduous journey of culture shock researchers and experiencers who seek to more fully understand the malady. Oberg's paper provides, after all, a accurate description of what he believes all sojourners experience.

Oberg outlines four stages through which all sojourners inevitably must pass before becoming accustomed to their new surroundings. He states that "culture shock is precipitated by the anxiety that results from losing all our familiar signs and symbols of social intercourse" (1960, p. 177). It is only by accepting the ways of the host culture, not necessarily at the expense of one's own ways, that one may overcome culture shock.

Oberg's four stages may be combined to form the U-curve that has become familiar to researchers in the area of culture shock. During the honeymoon stage (see Figure 1) the sojourner is at a pinnacle. Everything the visitor sees is new and exciting, the smells and sounds combine with the sights to create an exotic atmosphere. The hosts are friendly and tolerant of the expected oversights and blunders of the visitor, encouraging the visitors, providing guidance. But this "reinforcement by hosts diminishes as the novelty of the sojourner's behavior wears off" (Guthrie, 1975, p. 100), and the initial thrill begins to decline. 


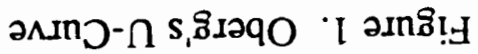

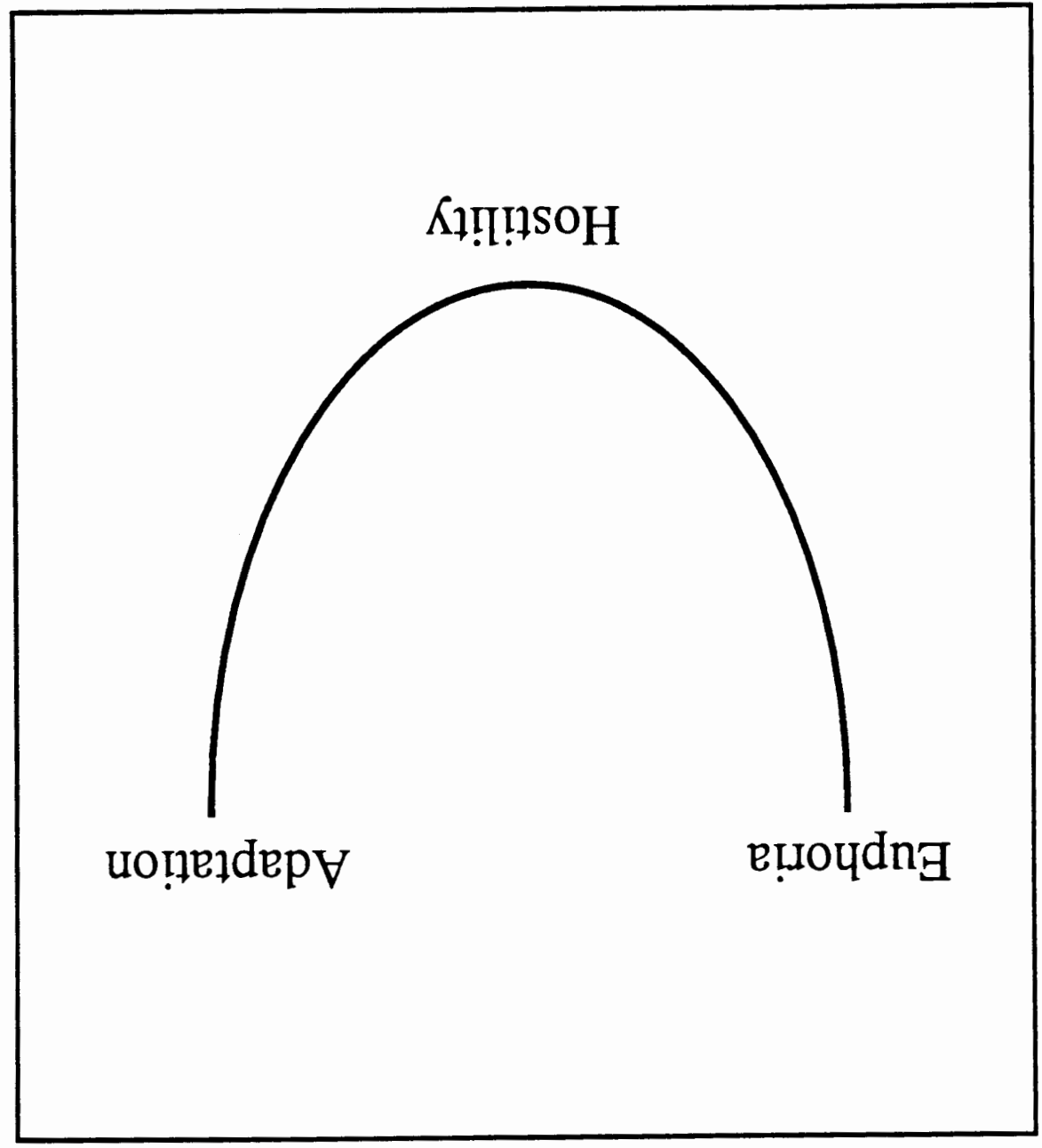


During the second stage of Oberg's U-curve, sojourners become disillusioned. As soon as sojourners begin to settle down in the new environment, feelings of hostility and aggression toward the host culture begin to set in (Oberg, 1960). The supporters who were initially available have gone back to their own lives, and the problems of the sojourners are their own to deal with. They begin to feel that their problems are caused by the hostile hosts who are certainly testing the meddle of the newcomer. This stage is typified by the turning of the visitors to enclaves of compatriots from which many sojourners never emerge.

In the third stage, the recovery stage, sojourners, much to their surprise, begin to adjust to their host's way of life. The language is no longer as formidable, a routine is established, and, most importantly, the sense of humor returns. Sojourners find themselves able to laugh about the problems they are having and to pity the poor soul who has just arrived on the scene, the new newcomer. Finally the fourth stage of the curve, the incline, arrives. During this stage, sojourners have adjusted. This stage is characterized by acceptance of the way of life of one's hosts. Although there remain moments in which the confidence of the sojourners may be shaken, they are able to proceed confidently through much of daily life, even to feel secure and at home in the now familiar surroundings.

Oberg's article is dated in that his discussion of culture shock symptoms focuses on tangible symptoms. His interpretation of complete adjustment to the new culture includes not only "a complete grasp of all the cues of social intercourse" (1960, p. 178) but also such things as acceptance of "the foods, drinks, habits and customs" of the host culture (1960, p. 178). There is no mention of the deeper psychological implications of culture shock which have been discussed more recently. And, most important for the purposes of this paper, language is mentioned only peripherally, as is usually the case in discussions of culture shock. I do not wish, however, to discredit Oberg's landmark work for it is indeed a crucial milestone on the road to understanding of this phenomenon. 
In brief, the U-curve analysis (Oberg, 1960) traces the stages of adaptation from elation to hostility or disorientation finally to gradual adaptation. A newer analysis, the Wcurve analysis (Gullahorn \& Gullahorn, 1963) adds to this curve the difficulties sojourners experience upon returning to their home countries (see Figure 2). The home country is at first surprisingly unfamiliar and disappointing, but gradually the sojourner begins to readjust. The reader may question the rather superficial discussion of the $\mathrm{U}$ - and W-curve analyses of culture shock presented here. I have chosen to not discuss them in detail because they are rather broad generalizations (Kim, 1989) of an extremely complex issue. It might even be argued that such prescriptive models and curves are dangerous for when sojourners experience something which is not accounted for in the model, as is inevitable, it is likely that their trauma will deepen (Weaver, 1986). While the two analyses present neat, graphic representations of the culture shock experience of sojourners and visitors who have returned to their native lands, they do not account for what is ultimately a very personal experience. The models do not account for individual differences which certainly will effect sojourner's experiences. Sojourners who return to countries in which they have already spent time may experience no culture shock at all. This applies as well to individuals who have travelled extensively -- a new country may be far less formidable to someone who is prepared to face, and to cope with, inevitable differences. The culture shock experience varies from individual to individual as well as from sojourn to sojourn (Bennett, 1977). The curves also take "no account of the more encompassing and progressive changes in identity which can ensue from the culture shock process" (Adler, 1975, p. 15). For these reasons, and for the reason given by Kim, the analyses do not warrant further mention in this paper.

One person who is addressing the issue of culture shock in a more personal and more modern way is Adler. He has written a number of articles which suggest that culture shock need not, necessarily, be a negative experience. Adler (1975) looks at the personal 


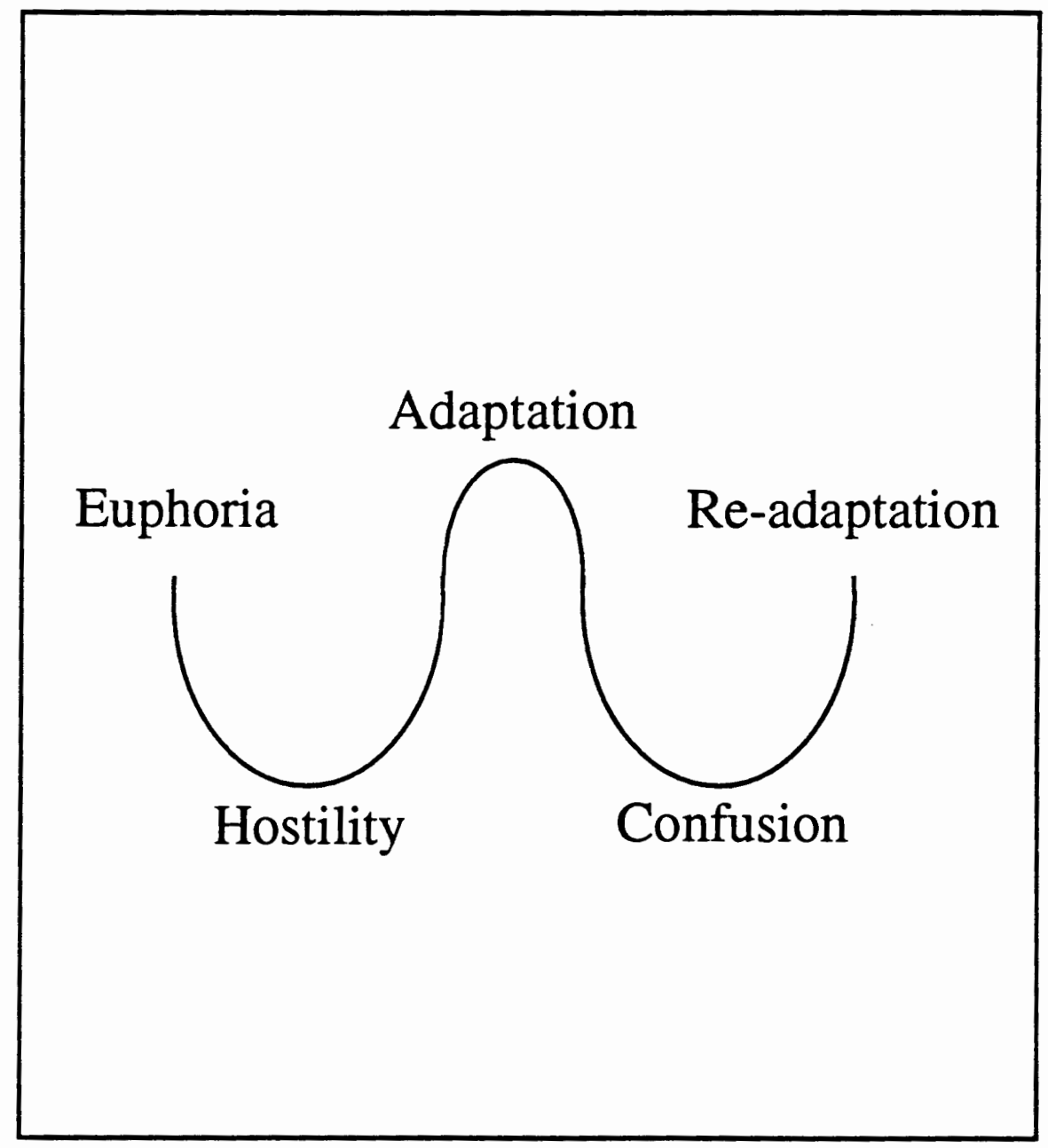

Figure 2. Gullahorn and Gullahorn's W-Curve. 
growth which evolves out of a successful grappling with the loss of that which is familiar, and contends "that the problems and frustrations encountered in the culture shock process are important to an understanding of change and movement experiences, and that such transitional experiences can be the source of higher levels of personality development" (1975, p. 14). This certainly represents a departure from Oberg's description of a malady and for the purposes of this paper provides a firm foundation from which to develop the hypothesis that the description of culture shock needs to be redefined. Adler's contention that culture shock is potentially a positive experience is the seed of what I hope will be the transformation of the anticipatory fear which accompanies the discussion of culture shock to the euphoric sense of adventure and discovery which should accompany the meeting of new people and ways.

Adler (1975) defines the stress of transitional experiences in stages which differ slightly from those of Oberg: 1) contact; 2) disintegration; 3) reintegration; 4) autonomy; 5) and independence. The two sets of stages are paralleled in Table 1 below. During the first stage, the sojourner is more attuned to similarities of the new environment with the familiar environment than to differences. In Adler's second stage, the differences become prevalent and overwhelming. The sojourner's "own cultural understandings are no longer appropriate and do not bring their expected results" (1975, p. 16). Adler's third stage is very similar to Oberg's third stage, characterized by hostility and rejection of the host culture and a retreat of the sojourner to compatriot enclaves. Adler's autonomy stage is characterized by a relaxation of the sojourner into the new environment. "The individual is a fully functioning person in his or her role and is both comfortable and secure with his or her status as an insider-outsider in two different cultures" (1975, p. 17). The important fifth stage that Adler has added to his paradigm includes a valuation of the differences and similarities of the host culture. Whereas in Oberg's final stage of adjustment the sojourner learns to live with the new culture, Oberg makes no mention of the value of the hosts' 
ways. Adler writes "the individual is fully able to accept and draw nourishment from cultural differences and similarities, is capable of giving as well as eliciting a high degree of trust and sensitivity, and is able to view both him- or herself and others as individual human beings that are influenced by culture and upbringing" (1975, p. 18). He discusses the implications of such a transitional experience, emphasizing that potential for growth does not promise actual growth. The conclusion he draws is common-sensical, but not one usually drawn in discussions of culture shock: "The more one is capable of experiencing new and different dimensions of human diversity, the more one learns of oneself" (1975, p. 22). This is a refreshing turn from the primarily negative connotations the term culture shock traditionally carries with it.

\section{TABLE I}

STAGES OF CULTURE SHOCK

\begin{tabular}{|l|l|}
\hline \multicolumn{1}{|c|}{ Oberg } & \multicolumn{1}{c|}{ Adler } \\
\hline 1. Honeymoon & 1. Contact \\
\hline 2. Disillusionment & 2. Disintegration \\
\hline 3. Recovery & 3. Reintegration \\
\hline 4. Adjustment & 4. Autonomy \\
\hline & 5. Independence \\
\hline
\end{tabular}

Two of the terms Adler uses to describe the stages of culture shock, disintegration and reintegration, are borrowed from Kazimierez Dabrowski, a Polish psychiatrist whose work is not well-known in the United States. His editor ranks Dabrowski among such noted psychiatrists as Erikson and Lindeman, but his theory of positive disintegration was not introduced to Western schools of psychiatry until thirty years after he had published in Poland in the 1930's and 40's because of the lack of relations between Poland and the United States. The relevance of Dabrowski's theory to this paper is significant. 
Dabrowski writes of biology and of the constant breaking down of entities to make way for the creation of new entities. "Throughout the course of life of those who mature to a rich and creative personality there is a transformation of the primitive instincts and impulses with which they entered life" $(1964$, p. 2). He wrote in the 1930 's, hence his preoccupation with biological notions, but his ideas are nonetheless relevant to my discussion. Most relevant to Adler's discussion, and to mine, are the following lines:

Disintegration of the primitive structures destroys the psychic unity of the individual. As he loses the cohesion which is necessary for feeling a sense of meaning and purpose in life, he is motivated to develop himself. The developmental instinct, then, following disintegration of the existing structure of personality, contributes to reconstruction at a higher level. (1964, p. 3)

Dabrowski acknowledges that "disintegration is used to refer to a broad range of processes, from emotional disharmony to the complete fragmentation of the personality structure, all of which are usually regarded as negative" (p. 5). But he disagrees with this negative regard, stating that the process of disintegration "is the ground for the birth and development of a higher psychic structure" (p. 5-6). In his own words "the theory of positive disintegration represents a change in the traditional psychiatric concepts of health, illness, and normalcy" (p. 23). This is the attitude we need to adopt in looking at culture shock. We need to look carefully at what is, in fact, debilitating about the experience so that we can realize that there is much to be gained from what has been mistakenly labeled a malady, a mental illness.

More recently, Adler (1977) describes the indelible link between individuals and their cultures. "Culture identity. . . is a fundamental symbol of a person's identity" (Adler, 1977, p. 26). Adler points out, for example, that while all human beings have basic biological similarities, it is the culture of an individual which determines the ultimate interpretation of human biology (1977). The notion of identity Adler presents in this article is different from Guiora's (1981), but both notions pertain to my argument that culture 
shock is a far more complex issue than was originally discussed by Oberg (1960). In other words, culture shock is not merely the result of being engulfed by new sights, sounds, smells and tastes. Becoming familiar with these will not necessarily alleviate the strain of culture shock. These tangible factors contribute to culture shock and are clung to because they are easily recognizable and definable components, but in addition to them, there exists a psychological upheaval, a calling into question that which has been familiar. With such questioning necessarily comes an unsureness about who one is. And because such questioning of self results from the experience of culture shock, some exploration into notions of identity, such as are raised by Adler $(1977 ; 1982)$ and Guiora (1972) must be included in culture shock research and explanation. Adler's notion of identity is dependent on culture for its formation; Guiora posits that language plays an integral part in the formation of a person's identity. And many researchers (Sapir, 1929; Geertz, 1988; Hall, 1981a, 1981b; Hymes, 1972) agree that language is inextricably intertwined with culture. If language and culture play such important roles in the formation of individuals' identities, then individuals will certainly experience discomfort, if not crisis, when language and culture are removed as happens in the case of a sojourn.

The focus of Adler's article (1977) is the multi-cultural man. Whereas traditionally one culture has shaped the identity of an individual, Adler posits that in the very near future the identities of multi-cultural persons will be open to and shaped by many cultures. Adler (1977) argues:

multi-cultural persons are not simply individuals who are sensitive to other cultures or knowledgeable about international affairs, but instead can be defined by a psychocultural pattern of identity that differs radically from the relatively stable forms of self-process found in the cultural identity pattern. (p. 38)

If the multi-cultural person is to come successfully into existence, then the issue of culture shock must be carefully addressed with demystification of the experience (Asante, 1989) as the primary aim of the research. Culture shock is probably inavoidable, but what can 
certainly be accomplished is a re-working of the focus of education on culture shock. Individuals should be prepared for the shock and should be taught to "use it in such a way as to make it a creative experience" (Asante, 1989, p. 97). If sojourners know ahead of time that they will be forced to call into question aspects of their being which they have heretofore been unaware of, then they will not be so shocked when they find themselves doing so. I argue in the last chapter for the integration of strategies into predeparture orientation that will enable sojourners cope with the shock they encounter, thereby enabling them to enter into intimate questioning, knowing that they will grow if they are patient and serious about the opportunity which is presented.

David (1971) presents another description of culture shock and of the ways in which this phenomenon may manifest itself. He discusses the various ways in which a foreigner may enter into a new culture, including the "enclave" sojourner (as in the case of American service people) and Peace Corps volunteers. It is the latter group, David states, that has "an opportunity for developing an unusual degree of self-awareness" (1971, p. 45) because of the degree to which they actually interact with the host culture. Many of the experiences of the two groups David discusses resemble those of the exchange students, although he does not specifically discuss exchange program participants.

A crucial point that David (1971) makes with respect to Peace Corps volunteers is that they rarely understand "how their 'individuality' is a reflection of their [U.S.] American values and learned behaviors" (p. 48). This point is crucial in the consideration of why culture shock occurs and should possibly be addressed in order to alleviate the severity of culture shock experiences. Most U.S. Americans consider themselves to be free of culture (Weaver, 1986). They know that their ancestors came from Germany, France, or Spain and they consider themselves still to be German, French or Spanish even if that ancestry dates back to colonial times. The United States is too often referred to as a melting pot of culture in which no culture remains discernible. Those sojourners from the 
United States who venture into new cultures do not think they will experience culture shock because they have no culture. Of course this is an erroneous notion. As I have stressed repeatedly, a person's culture plays an important role in the development of that person's identity. This is no less the case for U.S. American students than it is for their German, French and Spanish counterparts. Unless people are aware of the integral role culture plays in their development, they will not understand why they have such problems adjusting to the new cultures of which they have become a part.

Draguns (1976) also admits that the issue of identity is central to the manifestation of culture shock. He grounds his statements in theory but writes that "one of the most threatening potential consequences of contact with a new culture is the extent to which this experience calls into question the 'who' and 'what' of one's existence" (p. 5). Draguns considers individuals who have solidified their identity to be better equipped to withstand the impact that entry into a new and confusing culture is sure to have on the individual. This view is supported by Harris (1976) who writes that the mature, stable, flexible individual will have a less traumatic encounter with culture shock and possibly one of shorter duration.

More importantly, Draguns (1976) calls for a definition of the parameters of culture shock. As the definition now stands, the factors contributing to culture shock are potentially hundredfold. Such factors as climate population, financial considerations and situational adjustments may have nothing whatsoever to do with the new culture and may simply represent a change from what the sojourner is used to at home. Draguns points out that factors which are not culture related should not necessarily be included when evaluating the degree of culture shock a person encounters. This parameter setting is a vital aspect of the task of creating a definition of culture shock that researchers can work with in their efforts to better understand the problem. Certainly it is crucial to define exactly what it is one is investigating before one investigates it. Draguns closes his article with a call to 
approach culture shock "as a phenomenon and a concept, with the conviction that the insights gained will benefit" (1976, p. 8) those who embark on sojourning experiences. Sojourners need to know that the phenomenon of culture shock is inescapable, but the concept is understandable. An understanding of culture shock will enable sojourners to cope with it more effectively. It is important to note that such parameter setting as Draguns suggests follows the traditional model of culture shock. If the parameters are expanded though, as I suggest they should be, then such factors as are mentioned above must be considered to be just as important as cultural factors.

One researcher who places the experience of culture shock almost exclusively within the realm of the psychological is Harris (1976). Harris calls culture shock "the consequence of an abrupt challenge to the intactness of the self-image in the interpersonal environment" (p. 9). Those factors which are external, for example, the physical environment, the climate, the behaviors of the alien people, are only secondary in the manifestation of culture shock. Harris draws an important distinction between the experiences of the tourist and the sojourner based on this premise. Tourists do not experience the trauma of culture shock because they know that their visit to the foreign culture is brief and superficial and that they will return to their familiar environments soon. Sojourners, on the other hand, must immerse themselves in the new culture and must deal with the knowledge that a considerable amount of time will pass before they are able to return to the environment that is familiar to them.

The distinction that Harris draws parallels the call Draguns (1976) makes to define the parameters of culture shock. If one wishes to address culture shock as experienced by the sojourner, then one should not include the experiences of tourists in an evaluation. The two groups must be kept distinct because their experiences are ultimately very different.

Foster (1971) takes Harris' psychological grounding of culture shock yet further into the realm of the mind, calling culture shock a mental illness. The symptoms he notes 
are irritability, depression and annoyance because sojourners feel that not enough attention is being paid to them. "The victim usually does not know he is afflicted. . . [and] it rarely occurs to him that the problem lies within himself" (p. 187). This definition is drastic, but it is important to this thesis for two reasons. Most importantly, it focuses attention on the individual. Also, it brings culture shock into the realm of mental illness. While this is harsh, I will argue later in the paper that culture shock is a type of identity crisis. Identity crisis, once classed as mental illness (Baumeister, 1986), is now viewed in a more positive light, as culture shock should also come to be viewed.

Barna (1983) finally ventures into the realm of solution. In an approach similar to Adler's (1975), Barna compares the symptoms of culture shock with those of stress as defined by Selye (1974): "the nonspecific response of the body to any demand made upon it" (as cited in Barna (1983) p. 21). Barna suggests that cures for culture shock be sought in the areas where stress solutions have been found. She agrees with Guiora (1972) that empathy plays a central role in culture shock; in her view it is a key to the adaptation to a new environment. She calls empathy "the quality most often listed as necessary for successful intercultural communication experiences of any kind" (1983, p. 41). It is important to note that before one can empathize with another, one must recognize and accept the differences of the other. To do this, one must be able "to participate imaginatively in someone else's world view" (Bennett 1977, p. 49).

Weaver's (1986) discussion of culture shock is the most progressive and represents the greatest departure from such discussions as Foster's (1971), where the focus is on psychological ailments, and Oberg's (1960) who describes culture shock as a medical ailment. Weaver states that "ultimately the psychological make-up of the individual may be the most important factor" (1986, p. 122) in determining the adaptation success of that individual. But he focuses on the psychological in creative way, asserting later that "some have come to consider [culture shock] a normal and natural growth or transition process. 
As with any growth or adaptation, there is disorientation, ambiguity and pain, but we often come through this state more stable and centered than ever before" (1986, p. 113). Weaver likens the experience of culture shock to such psychologically disruptive experiences as changing schools or moving to a different city within our own countries. While they are disorienting, the disorientation is only temporary and generally one feels a sense of accomplishment when one successfully adapts to the new environment.

Weaver cites three explanations for the occurrence of culture shock. The first two, the loss of familiar cues and the breakdown of interpersonal communication are discussed by both Oberg (1960) and Adler (1975). It is the third explanation, identity crisis, which departs from the literature thus far reviewed, and focuses attention again on the individual. He calls this explanation "by far the most complicated yet the most fascinating" (1986, p. 118). Weaver designs his discussion of culture shock as precipitated by identity crisis around an analogy to computer programs ${ }^{1}$. Cultures, he claims, are like such programs. They tell people what steps to follow to fulfill their goals and to meet their needs. At each branch in the path an individual follows the program intercedes to guide the individual forward.

"When we enter another culture," Weaver writes, "the program which has worked so well since childhood no longer is adequate" (p. 119). We find that the program in which we had utmost confidence in our own culture turns out to be full of bugs when entered into the computer of the new culture. Sojourners become "overwhelmed by the bombardment of new stimuli and demands" (Weaver, 1986, p. 120) imposed by the new culture and find that they cannot deal with their surroundings. They find themselves in the midst of a crisis.

\footnotetext{
${ }^{1}$ I strongly disagree with Weaver's choice of analogy. Culture does not act upon human beings at all in the same way as a program acts upon a report. The relationship of human beings to their environment is interactive, not purely passive.
} 
But Weaver (1986) points out that it is precisely this state, the state of crisis, which "allows us to give up an inadequate perceptual and problem-solving system to allow another more expanded and adequate system to be born" (p. 120). This is the inspirational message for in its delivery Weaver points out that not only does the crisis mark the advent of creativity, but that sojourners are by no means faced with having to abandon their initial identities in order to facilitate assimilation to the new culture. Perhaps this can be clarified by way of analogy. To the engineer the language of the musician is foreign. But it is possible for the engineer to learn it. The engineer can study the vocabulary, learn what the correspondence is of notes to fingering and acquire the ability to play an instrument. Does the acquisition of the language of music mean that the engineer is no longer an engineer but a musician? Of course not. Rather, the engineer has acquired a new identity in addition to the old one. Such is also the case for sojourners. The assimilation of a new culture does not take place at the expense of the old culture, rather the old culture serves to benefit by being expanded to accommodate the new.

Weaver's analysis of culture shock marks a crucial departure from earlier analyses which focus on culture shock as a medical or psychological illness. But while he includes cultural identity in his discussion, a decisive characteristic of that identity is overlooked. One of the most distinguishing features of cultural identity is the way individuals speak. It is possible for them to enshroud their cultural identity in new costumes, but is is extremely difficult to mask their accents. The languages individuals speak provide them access to their environments and enable them to form and maintain their identities within those environments. This aspect of cultural identity is know as linguistic identity -- the identity one forms in and through the use of one's native language. This aspect of identity is as crucial to the understanding of culture shock as language itself is, yet nowhere in the discussion of culture shock is linguistic identity mentioned. The reader should bear the notion of linguistic identity in mind while reading the next chapter. Although my attention 
does not focus specifically on that aspect of identity until the fourth chapter, in the next chapter important points are made about the role language plays in defining who we are in our familiar environments.

Within the parameters of this brief chapter on culture shock literature, I have attempted to show that while research and models of culture shock have covered necessary arguments such as symptoms, possible causes, recommendations for coping with culture shock or adjusting to the new environment, the research and models are not sufficient for preparing sojourners for their time abroad.

They provide, however, a solid foundation from which to launch new exploration. In the next chapter, I will move away from the above characterizations of culture shock to a careful exploration into the contributions of linguistics, speech, social psychology, and psychology. By doing so, I will attempt to show the reader that language, with specific focus on linguistic identity, must be incorporated into culture shock research if culture shock is to be understood and dealt with more successfully by sojourners. 


\section{CHAPTER III}

\section{IN SEARCH OF EXPLANATIONS: A FORAY INTO FOUR AREAS OF INTEREST}

Learning to live in an alien society is much more than learning to speak a strange language, to eat unfamiliar food, and to observe different social customs. It involves a subtle but important change in one's expectations of oneself and of others. . . more important, one has to cope with a loss of identity and familiarity. (G.M. Guthrie, 1975, p. 95)

In the last chapter, I explored the literature on culture shock from the inception of the term (Oberg, 1960) to more current explorations (Adler, 1972; 1977; Weaver, 1986) with the intention of presenting the reader with a solid understanding of how culture shock research has evolved and where it stands now. What I will do in this chapter is look at culture shock from three points of view: intercultural communication, social psychology, and identity crisis. My reasons for choosing these particular areas will become clear as the reader peruses this chapter. In brief however, each area contains theories which directly relate language to possible explanations for why culture shock is an inevitable aspect of sojourning. Additionally, each of the theories presented here provides explanations which might be used in predeparture orientations to prepare sojourners for their encounters with culture shock. Because culture shock "comes under the domain of no particular discipline" (Adler, 1987, p. 24) it is necessary to consider many fields in order to create a complete picture of what people experience upon entering new cultures and why it is that they have this experience. Also included in this chapter is a section on Alexander Guiora whose construct, the language ego (1972), potentially fills a void in culture shock research. Guiora's language ego does not exactly match what I have referred to as linguistic identity, but the two are closely related. His construct also 
provoked many of the questions that have guided this particular research project. Because the construct has such important implications for the rest of the review, the first section of this chapter is devoted to Guiora. The construct is described and one of Guiora's experiments is discussed to show the direction in which he is pushing culture shock research.

The second section of this chapter focuses on work done in the field of intercultural communication. Within this field extensive research has been done to establish theories about how people communicate across cultures. For the purpose of this paper, I have focused specifically on uncertainty reduction theory (Berger \& Calabrese, 1975) which posits that the goal of communication between members of unlike cultures is to maximally reduce the uncertainty quotient so as to allow for more fluid conversation possibilities. Students, as well as other sojourners, spend a considerable amount of time trying to sort out what is happening around them and have, possibly more than other intercultural communicators, a pressing need to accomplish that goal of understanding. This section is also crucial because culture shock literature has not attended to the interactive nature of communication as defined in the first chapter. The field of intercultural communication acknowledges that for communication to take place, interaction must occur between individuals. This individual quotient is yet another factor neglected by culture shock researchers. Culture shock researchers have maintained until very recently (Weaver, 1986; Adler, 1975, 1977, 1987) that the symptoms of culture shock do not vary greatly from person to person. The experience of culture shock does vary though and the individuality of the experience ought to be incorporated into the paradigm.

The third section of the chapter, which focuses on social psychology, is particularly important because it contains information on an aspect of human existence which remains, for most people, completely unconscious. Social psychologists have 
done extensive work on roles, social group theory and social identity, factors which are integral to the success an individual has in entering a new environment. But if these notions are not brought to the conscious level of understanding for sojourners, they present a tremendous obstacle to the sojourner's understanding and processing their experiences.

The fourth and final section of the chapter is comprised of a discussion of Baumeister's (1986) ideas on identity crisis. Whereas culture shock is not traditionally recognized as being this type of crisis, it is remarkable how much similarity there is between the symptoms Baumeister discusses and those that culture shock researchers discuss. Identity crisis is a formidable term which is surrounded by negative implications, but, curiously, it is the contention of a number of researchers that the positive, creative implications of such crisis far outweigh the negative implications.

Although the areas included in this chapter are diverse, they are powerfully connected to the exploration of culture shock and, as I mentioned in the conclusion of Chapter II, they explain the role native language plays in the formation of identity. Language is integral to the success of human interaction but, as will be shown in the presentation of each of these four topics, we may not always be aware of how profound its effect is on that interaction. One researcher who has focused his attention on the link between language and personality is Guiora. Because his work was the catalyst which provoked this research and because it provides a provocative plunge into the discussion, a review of Guiora's work is presented first.

\section{ALEXANDER GUIORA}

Alexander Guiora has concentrated on deciphering what role personality plays in adult second language acquisition. In 1972, Guiora, Brannon and Dull reported the results of a number of experiments done with Defense Language Institute (DLI) students 
to determine what role empathy plays in adult acquisition of second languages. The authors state that "empathetic capacity is related not only to pronunciation ability, but also in yet to be determined ways, to the overall capacity to acquire a second language (Guiora, Brannon \& Dull, 1972, p. 113). For earlier research Guiora, Brannon, and Dull hypothesized that pronunciation, in their regard the most critical language skill, is the most "salient aspect of the language ego" (Guiora, Brannon \& Dull, 1972, p. 112). The purpose of the DLI research project was to measure empathy in the subjects and to test the level found against the individuals' ability to acquire a second language, in this case focusing exclusively on pronunciation. The researchers hypothesized that those subjects who ranked high on tests of empathy would also rank high on an Authenticity of Pronunciation (AP) test. The subjects were given six tests designed to measure receptiveness to interpersonal cues of affective states, empathetic activity and accuracy, personality factors, and verbal concept manipulation ability. A general questionnaire was also administered to "obtain demographic, motivational, and previous language experience information" (Guiora, Brannon \& Dull, 1972, p. 120).

Three months after these tests had been administered and scored, and after the subjects had been participating in language instruction at DLI, Phase II of the experiment was conducted. The subjects were given the AP test which consisted of "a script composed of ten words and ten sentences in each desired language... each word and sentence having from one to three predetermined points of pronunciation difficulty" ( $p$. 120). While their experiments were successful and persons with higher empathy ratings did score highest on the AP test, Guiora, Brannon, and Dull were reluctant to interpret their results because of the small size of their subject groups. They also found that "the attempt to predict authenticity of pronunciation on the basis of data pooled for all languages was relatively unsuccessful" (p. 126). Nonetheless, their hypotheses and the research conducted provide questions which support my opinion that language and 
identity are more closely entwined with one another than has heretofore been acknowledged. A later article by Guiora further underscores this notion. The concentration these researchers give to the relationship of language to identity underscores the absence of attention paid to this relationship in culture shock literature and suggests that the relationship should be paid greater attention in research on culture shock. Their determination that an important link exists between language and culture supports my theory that language plays an important role in the experience of culture shock. If such a small aspect of language like pronunciation plays as significant a role in the adaptation success of sojourners as Guiora, Brannon and Dull suggest, then certainly language as a whole plays an even more crucial role. Indeed, Guiora (1981) contends that "speech -- speaking a native language -- is a powerful dimension of selfrepresentation" (p. 171). It is through the native language that people communicate their SELVES to each other which, as will be discussed in the next chapter, is vital to our understanding of where we fit into our society in relation to those with whom we come into contact. Language acts as mediator between coexisting persons everywhere, therefore sojourners must be made aware of its importance if they are to anticipate the difficulties they will face abroad and will be able to grapple with them successfully.

While the thought that language so greatly influences the personality of each individual may at first seem overwhelming, Guiora (1981) provides a reassuring argument. He focuses his attention on the Sapir-Whorf hypothesis for the purpose of taking the hypothesis one step further. Guiora posits that although the native language influences the shaping of an individual's personality, that personality remains open (in varying degrees) to the effects of new influences (e.g. new languages, cultures, experiences). The points Guiora makes are crucial to the investigation of the relationship of personality and language. Guiora refers to his own construct, language ego, which might be described as the identity one develops in and through the language one speaks. 
Guiora believes that language is absolutely central to the development of an individual's personality and explores the extent to which exposure to other languages presents the individual with conflict. Perhaps most salient to this thesis topic is Guiora's call for "systematic inquiry into the principle of linguistic and cultural relativity" (1981, p. 171). Despite Guiora's call ten years ago, for research into the connection between language and culture, culture shock researchers are only just beginning to integrate this issue into their research. Weaver $(1986)$ and Adler $(1975,1977,1987)$ are foremost on this quest; others ought to follow suit. In this thesis I will attempt to demonstrate how closely language and culture are related and what potential impact the acknowledgement of that relationship has on future predeparture orientation courses.

Guiora, Brannon and Dull (1971) maintain that learning a second language is an "act of extending the self so as to take on a new identity" (p. 112), but in saying so mean that "one of the basic modes of identification by the self and others [is] the way we sound" (p. 112). It is important to note that the hypotheses and research of this particular group for the most part stay rooted in the physical - in the actual production of authentic sounding second language. They state that the peculiar sounds and uncomfortable mouth movements that students of second languages have to make may present problems "extreme enough to create feelings of a loss of identity" (p. 115). But their concern with the identity of the individual learning a second language ties their hypotheses to my own. They admit that "second language learning in all of its aspects [italics added] demands that the individual, to a certain extent, take on a new identity" (p. 113). It is this statement which the reader must keep in mind as this paper unfolds.

Guiora and his colleagues have focused on individuals and their ability to produce authentic sounds. But, as was defined in the first chapter, communication involves more than one individual. There must be at least two individuals present for communication to even be attempted. Researchers in the field of intercultural communication discuss 
precisely this - the transfer of information from one, or more, individuals to others. What separates this branch of research from other communications branches is that the focus is on communication between different cultures - culture shock experiencers are individuals who must communicate with people from different cultures by way of foreign languages.

\section{INTERCULTURAL COMMUNICATION}

Within the field of intercultural communication, my primary focus of research has been the theory of uncertainty reduction. I have chosen to focus on this theory because much of the struggle exchange students encounter involves the sorting out of peculiar new ways of doing things so as to better understand what is happening around them. This is exactly what the theory of uncertainty reduction addresses. Proponents of this theory state that in the initial encounter of strangers, the primary goal is the reduction of uncertainty which otherwise hinders communication success (Berger \& Calabrese, 1975; Gudykunst, Kim \& Chua, 1984; Gudykunst \& Ting-Toomey, 1988; Goldsmith, 1992). Although the theory has been subjected to a good deal of criticism on the grounds that it is a western theory which presupposes that uncertainty is undesirable rather than possibly an actual goal of conversation (Gudykunst, Kim \& Chua, 1984; Goldsmith, 1992), Berger and Calabrese have defended their theory as far as Western cultures are concerned. Since it is to those cultures that I have limited the scope of this paper, it is appropriate that I refer to the theory. The definition of communication given at the beginning provides support for the theory as well, for if revealing ourselves to others is the goal of communication, then uncertainty must be reduced.

An understanding of schema theory may facilitate the discussion of uncertainty reduction presented below. Celce-Murcia (1986) writes that "in trying to understand the experiences in our lives, our internal mental systems attempt to see the connections between events that make up our experience" (p. 176). These connections are packaged 
together in our minds into units known as schemata. Schemata enable us to better understand the events we witness and participate in. Events for which we possess no schemata may seem quite strange and difficult to comprehend. Schema theory plays an important role in uncertainty reduction for by developing or learning the schemata for unfamiliar events or sequences of events we are able to reduce uncertainty and begin to understand that which seemed strange.

Berger and Calabrese (1975) distinguish between two different types of uncertainty: uncertainty about how a stranger will behave, and uncertainty in explaining retroactively the behavior of the stranger. Gudykunst and Ting-Toomey (1988) have elaborated on this initial model and it is on their model that I have concentrated since it incorporates Berger and Calabrese's types.

Uncertainty, according to Gudykunst and Ting-Toomey (1988), involves two phenomena. The first of these phenomena is the "individual's inability to predict their own and others' beliefs and attitudes" (Gudykunst \& Ting-Toomey, 1988, p. 22). It might sound fantastic to declare that individuals are incapable of isolating their own beliefs and attitudes, but in fact this is very much the case. We are so closely tied to these beliefs and attitudes that we rarely, if ever, realize what integral roles they play in our daily encounters with other individuals. It is virtually impossible to be aware of which attitudes are affecting what we say and do at any given moment. No amount of introspection will reveal this information to us.

A simple example of how deeply engrained beliefs and attitudes are can be found in the following story. Last Christmas an Indian friend returned home to marry a woman he had met only four months earlier. It was a union that had been arranged by the parents of the couple. Deeply involved in a traditional U.S. American relationship, I could not fathom the fact that my friend was so relaxed about his impending marriage. My impression of the society in which I had grown up was that men and women married and 
divorced as often as they changed jobs or moved to different towns. The 35-year marriage of my parents was certainly the exception. Nonetheless, I had grown up with the expectation that I would choose my mate, and that we would decide if and when to get married. Our parents would play fairly peripheral roles in the decision.

As my friend explained to me though, he had grown up with the expectation that his parents, two people in whom he had the utmost trust, would arrange his marriage to a suitable young woman. Although each of the young people would be given the opportunity to choose to not marry the chosen partner, young people usually accept their parents' choice and marry. Incredibly, my friend reports that most of them stay married all of their lives and raise large and contented families together. In fact, my friend considered himself very lucky because he was able to meet his future wife before the wedding. His parents had met on their wedding day, during the ceremony.

Until I had this conversation with my friend, my marriage schema did not include arrangement by parties other than the marrying individuals; I never would have considered the possibility that an arranged marriage could have any positive attributes. But our conversation enabled me to understand that my expectations were rooted in the individualistic beliefs of my culture in which, after the age of eighteen, young people are believed to be independent enough to make such important decisions as with whom to spend their lives. Participation by the parents is usually viewed as interference. In the Indian culture, young people accept and are grateful for the intervention of their parents. It is a culture in which the family is central, not the individual, and the recommendations of that unit are taken very seriously.

The second aspect of this phenomenon is also tied to the above story - it concerns the ability of an individual to determine the beliefs and attitudes of a stranger. Human beings are incapable of determining what others are thinking, and although we draw conclusions based on what information is immediately available to us regarding a 
stranger (style of dress, posture, possibly social status given the scenario of the initial encounter), who the individual really is remains a mystery. The impending marriage of my Indian friend forced me into a position of uncertainty. I was unable to determine what his beliefs and attitudes were so I simply attributed my Western beliefs and attitudes to his society. The conclusion I drew based on that attribution was that arranged marriages were something to be protested. Until I spoke with him, I viewed the possibility of an arranged marriage for my friend without a grain of understanding.

Sojourners will often find themselves in similar positions to the uncertain one in which I found myself. As I will discuss in the next section, being able to place a person in, or indeed outside of, social categories is crucial to successful interaction with that individual. Sojourners are forced to make determinations about their hosts without the benefit of much background information. They therefore experience a far greater degree of uncertainty about how to act within the bounds of that culture. Reducing sojourners' uncertainty about the beliefs and attitudes of host culture members will greatly enhance their ability to understand the necessary social categorization. Additionally, if sojourners are exposed to the fact that their language has played an integral part in the formation of the concept they have of themselves, they may be able to understand better what is peculiar about their hosts. From the example presented above of my conversation with an Indian friend it is clear that even on a superficial level, language played a crucial role in my understanding of a custom peculiar to his society. If I had not had the opportunity to discuss the customs of my friends' culture, I would not have come to understand them as I am now able to. Indeed the heading of this section intercultural communication indicates that language is central to these issues. Language is used, in both verbal and non-verbal form, to accomplish much of the uncertainty reduction discussed here.

The second phenomenon involved in the discussion of uncertainty concerns the successful prediction of behavior on the part of both parties. When two individuals 
encounter each other for the first time they make predictions, consciously or unconsciously, about how the other will behave, and about what the other's beliefs and attitudes will be. Additionally, after such a meeting, each individual will reflect on it and will try to explain, retroactively, the behaviors, beliefs and attitudes of the other (Gudykunst \& Ting-Toomey, 1988). When the ways of a stranger are unfamiliar to an individual, that individual will have a difficult time anticipating the behavior of the stranger. What people usually do in such a situation is project their own potential behaviors onto the stranger and expect that individual to behave as familiar people would behave. When this does not occur, when the stranger does not behave in an anticipated manner, uncertainty is perceived and both individuals go on guard. This is the crucial point at which communication will either break down or cooperation will begin. If the individuals are unsure of themselves then communication will probably break down. But if one or both people are confident in themselves cooperation may begin. Individuals must have high degrees of self-confidence if they are to successfully encounter a stranger and risk mistakes or miscommunications long enough to find out what is expected behaviorally from the other.

Gudykunst and Ting-Toomey (1988) suggest three strategies for reducing uncertainty. The first is a passive strategy. One observes the behavior of one's hosts long enough to make an assumption, an informed assumption not an impetuous one, about how one's hosts behave. An understanding of the connection between language and culture will have a profound effect on the individual who seeks to understand a new people in this passive manner. If individuals are able to think about how their languages govern their ways of life, then the task of understanding their hosts may be made easier. The second strategy follows a more active approach. Information about the host culture is sought from resources outside the host culture. This strategy might be employed before one embarks on a sojourn in preparation for the trip. In any case, the visitor asks 
others who are perhaps more familiar with the host culture for information about the expected behavior, the beliefs and attitudes. It is through this type of strategy that conscientious visitors arm themselves. One scenario in which sojourners should have the opportunity to ask such probing questions is in predeparture orientations. As will be discussed in Chapter V, the task of the predeparture orientation leader should be to expose students to the linguistic identity of the host nationals as well as to their cultural identity in addition to encouraging the students to explore and acknowledge their own linguistic and cultural identities.

The third strategy is interactive. It is by employing this strategy that the visitor involves the hosts directly in the collection of information. The behavior of the hosts is questioned and information is elicited. This tactic enables visitors to exhibit curiosity and interest in the host culture while at the same time encouraging their hosts to recognize that their ways are different from the ways of the visitors. This is something that might not occur to the hosts who are carrying out their daily tasks in the usual manner.

These three strategies are not sufficiently addressed in pre-departure orientation. The focus of many of these programs is on presenting a collection of solutions for how to deal with culture shock rather than on arming the sojourner with strategies which are adaptable to the many and diverse culture shock encounters each individual will undoubtedly have. La Brack (1986) describes orientation as a "one-time, rather static set of prescriptions, simulations, and 'do-don't lists" which needs to be revised (p. 226). The strategies Gudykunst and Ting-Toomey suggest provide an excellent starting point for the development of such empowering techniques.

Gudykunst and Ting-Toomey (1988) also differentiate three levels of understanding which they say involves "the ability to make accurate descriptions, predictions, and explanations" (p. 23). First the visitor must be able to describe the behavior, belief or attitude which has caused uncertainty. Description is a task which 
encourages the individual to look carefully at what seems confusing or out of place. It also encourages the individual to try to make sense of what may appear to be nonsensical. Once the peculiarity has been described, then the visitor must predict. Although "we are not always aware of making these predictions" (Gudykunst, Kim \& Chua, 1984, p. 23) we do so constantly in our everyday interactions with acquaintances and strangers alike. Communication involves the making of predictions about what will come of our attempts to express needs, ideas or emotions to others. The more aware we are of possible alternative outcomes, the more predictions we make about the outcome of our communication. Finally, one must find an explanation for what one has observed. It is only by being able to complete these three tasks that one may truly say one understands a particular situation. If sojourners have an awareness of the profound effect their own native languages have on their daily life, then they will be better able to attempt describing, predicting and explaining the actions of their hosts.

Nisbett, Caputo, Legant and Marecek (1973) discuss point of view, which they say further complicates successful communication, the interpretation of a message as the sender intended the message. These authors point out that the sender and receiver of a message perceive their own and each others behaviors quite differently. In their words "actors tend to perceive their behavior as a response to situational cues, while observers tend to perceive the behavior as a manifestation of a disposition or quality possessed by the actor" (p. 154). Actors behave in a particular way based on their interpretation of a situation. They consider the environment, the roles of the people with whom they are attempting to communicate, any prior experience they have had with these people, and what they perceive their own role to be within the situation. They then act according to what the particular situation demands. Observers, though, do not absorb the situational cues in the same way, rather they focus exclusively on the behavior of the actor 
attributing it to some inherent characteristic of the actor. Observers therefore lack a great deal of the information needed to evaluate a situation. Actors possess this information.

This point of view difference carries with it important implications for the intercultural communication situation. Sojourners, as actors, lack crucial information to which they are usually privy about how to act in given situations. They do not, at the outset, have prior experience with members of the culture so there is nothing on which to base communication attempts other than what they are familiar with from their own cultures. Rarely do sojourners have access to host culture expectations about social roles, so again they must rely on what they are familiar with from the culture they have grown up in. Only very rarely does the background information one brings from home apply in a new culture, regardless of how similar the culture appears to be to one's own culture. The hosts, as observers, will attribute the peculiar actions of the sojourner to some personal attribute of the individuals, not considering that the individuals are acting as they know how to based on the cultural norms of their native cultures (Nisbett, Caputo, Legant and Marecek, 1973, p. 154).

During orientation programs, sojourners are usually made aware of the fact that they will lack the crucial information discussed above. Seldom, though, are they prepared for the possibility that their hosts will attribute the sojourners' actions to personal attributes rather than to the culture of the sojourner. The German student, for example, who sneezes at the dinner table and does not excuse herself might be labelled rude by her host family if they do not realize that in Germany it is not considered necessary to excuse oneself after sneezing. The individual is held responsible, in this case, for a societal difference. Sojourners often complain that they feel personally attacked during the second stage of culture shock. What they must be brought to realize, ideally during an orientation program, is that what they feel stems from the hostobserver's lack of knowledge of the sojourner. 
Gudykunst (1984) discusses Nisbett, Caputo, Legant and Marecek's (1973) paper and the issue of information possession: "another explanation for the differential bias of actors and observers stems from a difference in the nature and extent of information possessed" (p. 25). Actors always know more about themselves than do their observers. In an intercultural communication situation, the sojourner and the host must each give the other ample opportunity to explain why they behave as they do. Both groups must realize that the other group possesses information which is vital to the success of their communication. Sojourners must realize that their hosts possess the solution to the mysterious ways of the new culture and that careful and patient observation and inquiry, as explained by Gudykunst and Ting-Toomey (1988), will open for them a new world.

This does not, however, mean that the hosts must take on the responsibility of explaining their ways to sojourners. It remains the responsibility of sojourners to approach their hosts if they want to understand the culture of which they have become a part. It is in the hands of the sojourner to seek out "a host national who is sympathetic and understanding" (Kohls, 1984, p. 70) with whom to discuss the complexities of the new culture. It is the responsibility of sojourners to make sense of the apparently senseless ways of their hosts, after all, the hosts are following their routines -- the few sojourners they encounter present no real problem to them. Kohls' recommendation to the sojourner is to remember that "your problem lies in your relationship to the host culture" (p. 70) not the reverse.

The strategies outlined by Gudykunst and Ting-Toomey have the potential to play a vital role in sojourning preparation. Armed with these strategies, the sojourner can enter a new culture better prepared and more capable of dealing with peculiar situations that arise. The strategies empower the sojourner to approach members of the host culture and to request information about experiences which are perplexing. An understanding of that part of the self which is connected to the language one speaks, the linguistic identity, 
or at least an awareness of its presence, will ease this task. As Kohls suggests, the informer should be sympathetic and understanding. Additionally, the sojourner should be aware of social grouping, and status considerations. Social psychologists provide insight into these topics which is necessary for the sojourner to have.

\section{SOCIAL PSYCHOLOGY}

Although Guthrie, whose words open this chapter, does not specifically address the issue of culture shock in his article, he succinctly summarizes exactly what is central to that crisis in that opening statement. With the loss of those aspects of life which are most familiar (Oberg, 1960) and usually most unconscious, sojourning individuals begin to question who they are and what exactly they are becoming, what roles they are to play and to which groups they belong. Social psychology is the field of inquiry in which these topics are discussed and it is to the social psychologists I turn for information on social roles, social groups and social identity.

Individuals fill the roles of many diverse characters in the course of a day; certainly hundreds of roles are filled in a lifetime of a single individual. The roles may be biologically determined e.g. sex, age, ethnicity. They may be determined by such factors as marital status, family status, occupational status, and leisure time activities. And they will vary from moment to moment and from day to day depending on the type of interaction the individual is involved in. These roles are not determined by the individual person, rather they are representative of the usual way in which people who are filling the role usually do things (Olmsted, 1961). As Olmsted points out, "there is an element of similarity in the behavior of people cast in similar roles who in other ways may be quite diverse" (1961, p. 21).

These roles are culture specific and although they may be similar across cultural boundaries, the expectations of each society are so different that the same role, for 
example the role of mother or father, may not be recognizable across a cultural boundary. At first glance, it might appear that a particular role with which one is familiar does not even exist in the new culture. This will certainly be a disorienting experience for the individual whose role appears to have been removed.

As I have stated, roles are filled according to the expectations of a given society. For example, many parents of U.S. American university students expect their children to be independent: to live away from home and to support themselves through school. The parents of German students expect to play more involved roles in the lives of their university age children, supporting them through their education. The German students may work, but their parents and the government will be the primary forms of support. The reason parents and children manage to successfully fill their roles is that the expectations of all participants within the two societies coincide. As Olmsted (1961) states, "these expectations may be quite definite and mutually viewed as binding, even though never explicitly verbalized" (p. 22). We learn as children what our roles are and what is expected of us when we fill each role. As we grow older, our roles change and we add new roles to our repertoire, but amazingly, things continue to run smoothly regardless of how many roles we master. Our roles help us organize our lives and enable us to see where we fit into the scheme of our culture. They enable us to make quick judgements about determining how best to act in a given situation (Olmsted, 1961). The conclusion I draw from this brief exploration of social roles is that we derive confidence and self-assurance from them and can function contentedly within the fishbowl of a familiar world as long as we abide by the expectations that society has of the roles we fill.

A breakdown in this neat system occurs when one enters a foreign culture. Foreign in this case by no means refers exclusively to the case of an African entering the world of an Arab or of a European entering the world of a South American. Foreign could be something as simple as a middle class white North American entering the world 
of the court of law for the first time. If that North American lands the role of juror then the actors' notes are explicit. But the situation is different if the role of defendant is won. A lawyer will act as a coach, but there are few explicit guidelines provided from which one might derive confidence. Olmsted (1961) points out that expectations of behavior must be relatively similar for both parties if the interchange is to be successful. If the expectations vary, even slightly, there will certainly be conflict. "In such circumstances motives may be misinterpreted, and different persons may arrive at quite different conclusions concerning the ethics or propriety of behavior or even the actual content of mutual experience" (Olmsted, 1961, p. 22).

The experience of a student involved in a study aboard program is similar to that of the defendant. There are orientation programs, and guidelines and veteran exchange program participants from whom the new exchangers may gain some insight into what their new roles will be, but ultimately it is up to the student to decipher the new system. The student is sure of the student role at home, but how is that role to be played out at the new university? Students in the United States still enjoy a relatively personal atmosphere at the university where classes may yet be small and the student will have the opportunity to participate in class and receive personal attention from the professor. Winter (1986) reports that "for a professor to be concerned about the students' welfare, both personally and academically, [is] a totally new experience for many German students" (p. 315). In German universities, where the classrooms are overflowing and many students have access to lectures only via impersonal sound systems, there is an air of anonymity. "It is usually expected that particularly gifted students find their own way to the top and develop their own thoughts about the future research projects which they would like to do" (Winter, 1986, p. 315-16). Both U.S. and German students who study abroad will have adjustments to make to their expectations of the role of the student when beginning to study at the new university. These students may also wonder about the role of 
professors. A U.S. American student who attends a European university for one year will certainly be surprised at the formal, often stiff, atmosphere of the host university. Access to professors is severely limited and most professors remain very aloof when dealing with students. Students must be aggressive if they want to receive the Schein (the official grade notice) and frequently will have to inquire as to what work is expected of them. Whereas U.S. students frequently come to call their professors by first names and have friendships with them as well, German students usually refer to their professors as "Professor" if not "Frau Professor" or even "Frau Professor Doktor". The European student, on the other hand, may feel stifled by the U.S. professors who frequently expect participation from all of their students. The plethora of mid-terms and papers and projects is often overwhelming and the frequently arriving deadlines may seem insulting to students who are not used to being pursued in such a manner (Winter, 1986).

Just as people fill many differing roles in the course of their lives, they are also members in many social groups simultaneously. This entity, the social group, is difficult to define. A group might be defined as Tajfel (1981) did: "a cognitive entity that is meaningful to the individual at a particular point of time" (p. 254) or as Tajfel and Turner later (1992) suggest: "a collection of individuals who perceive themselves to be members of the same social category" (p. 116). Gudykunst (1984) draws a distinction between the kinds of groups to which we belong and those to which we aspire. He calls the former set of groups "membership" groups and the latter set "reference" groups. A further distinction which is made (Gudykunst, Kim \& Chua, 1984; Gudykunst and TingToomey, 1988; Tajfel, 1981) is the distinction between "in-groups" and "out-groups". The former groups are those with which we associate; from the latter we are taught to distance ourselves (Gudykunst, Kim \& Chua, 1984). It is crucial to note that this delineation of "in-" and "out-" groups is thought to be universal among humans (Brewer and Campbell, 1976) so it must be assumed that the various groups each play important 
roles in how we organize our world. As might be expected, we elevate our in-groups to a superior position and expect that the members of those groups will fill their roles in a predictable manner. The impressions we form of the out-groups are based on stereotypes which, while helpful in forming initial impressions, frequently become dangerous and misleading caricatures of reality if they are not tempered with actual exposure to the group. Gudykunst draws a distinction between two types of stereotypes: normative and nonnormative. The normative stereotypes are formed on the basis of information provided by media and historical occurrences. Nonnormative stereotypes are formed when there is little information about the out-group available from these sources. In these cases we assume, if the group is friendly, that it is similar to ours and we project our image of ourselves onto the members of the out-group. If friendly relations do not exist, then we will seek media and historical intervention and will form a normative stereotype.

One way of delineating groups is through the use of language. Parents of teenagers lament the fact that they cannot understand their children. This is due to more than just the rebellious attitudes of the children. It is due largely to the fact that teenagers speak in a language of their own which is comprised primarily of slang words whose lifespan is short. The lexicon of this language changes so rapidly that it is nearly impossible to learn quickly - one must be part of the culture in order to acquire it. Members of the medical profession and of the judicial system speak jargon which is often impossible for laymen to understand. These professional jargons, the slang of teenagers, also the dialects of such groups as Afro-Americans serve to underscore group boundaries. If one cannot talk like a particular group then one is automatically viewed as an outsider (Giles \& Powesland, 1975).

This delineation of group boundaries by speech styles carries grave implications for sojourners. Any sojourner who cannot speak like a native will be labelled outsider. Even sojourners who have studied the new language prior to their departure will only 
gain insider access to groups after having acquired the necessary slang, jargon or dialect (Wardhaugh, 1992; Bernstein, 1964). These are aspects of language which are only minimally accessible in language classrooms.

Lacking the linguistic access to insider status, sojourners are temporarily outsiders in their new cultures. By default then, the groups to which they cannot gain access become out-groups. Because the unfamiliar ways of the out-groups appear to be threatening, we cling to our in-groups for acceptance, reinforcement, security. "Social groups... provide their members with an identification of themselves in social terms. These identifications are to a very large extent relational and comparative: they define the individual as similar to or different from, as better or worse than, members of other groups" (Tajfel \& Turner, 1992, p. 116). These distinctions are clear and dependable until one leaves the comfort of the familiar groups and environment. Tajfel and Turner (1992) point out that these social groups "provide a system of orientation for selfreference: They create and define the individual's place in society" (p. 116).

What happens, though, to students who are transplanted from an atmosphere in which in- and out-groups are familiar and predictable into an environment where those distinctions are not clear? How are students to determine to which group(s) they belong? How will they determine how to act within the new in-group? Which groups are the out groups? How are the students to react to the members of those groups? Suddenly many of the supports are gone, there appears to be very little to rely on, and the confidence students may have felt at home is severely shaken. There is little wonder that exchange students and other sojourners form enclaves (Asante \& Barnes, 1989; David, 1971) of "little Germany's", "little Oregon's", "little France's" in an effort to rebuild whatever they can of the familiar in-groups to provide the support each of the individuals is used to receiving from the in-groups at home. These social groups are vitally important for our survival, but our association with them is curiously unconscious. The familiar old saying 
applies: "You don't know what you've got 'til its gone." We move fluidly from group to group and rarely experience a situation in which some group support is not present. We are not necessarily aware, though, of how much support they lend, so when we move away from them we are startled to find ourselves quite unstable.

The notion of social groups, and specifically the support they give to each individual, plays an integral role in the development of social identity (Gudykunst, Kim \& Chua, 1984; Gudykunst and Ting-Toomey, 1988; Tajfel, 1981; Tajfel and Turner, 1992). Social identity is defined by Tajfel as "that part of an individual's self-concept which derives from his knowledge of his membership of a social group (groups) together with the value and emotional significance attached to that membership" (1981, p. 255). In other words, we define who we are based on the groups with which we affiliate ourselves and on a comparison of those groups with our reference groups. If our ingroups compare favorably to the reference groups, then we develop positive self-images. If this is not the case, we make an attempt to leave the group which does not compare favorably (Gudykunst, Kim \& Chua, 1984). While this identification of oneself through affiliation with groups may appear to be rather faddish, Tajfel (1981) acknowledges that "however rich and complex may be the individuals' view of themselves in relation to the surrounding world. . some aspects of that view are contributed by the membership of certain groups or categories" (p. 255).

This social identity is quite closely related to Guiora's language ego. It is through socialization, introduction into the various social groups of which we are to become members, that we come to understand who we are and one of the chief tools of this process is language. As Guiora (1981) stated "native language is one of the critical rings of identity" (p. 172). Through this language we establish ourselves as individuals and without that language to rely on we may find ourselves quite abandoned. For sojourners this abandonment manifests itself on three levels. First, they find that the language on 
which they have relied all of their lives is no longer reliable. It has, in essence, abandoned them because it can no longer aid them in interpreting the behavior they witness. Additionally, sojourners find that they cannot present themselves to their hosts in ways to which they are accustomed because the hosts do not understand their humor, their style of prose, etc. Second, sojourners find that after their initial contact with their hosts, the hosts return to their lives and, in doing so, abandon the sojourners. Finally, sojourners are abandoned by the social structure they have come to rely on at home. In the new culture they are unable to determine what their roles are or what are the roles of their hosts. Consequently, they are left outside of the cultural framework.

This notion of abandonment is at the heart of the experience of culture shock. Upon entering a new culture, sojourners must become confident in the new language enough to rely on it instead of their native language. They must understand that their hosts return to their daily lives because they must do so, not necessarily because they find the sojourners intolerable. Finally sojourners must learn new roles, establish membership in new groups, and learn new ways of behaving so as to carve for themselves a place in the cultural framework.

Closely related to learning new modes of behavior [are] anxieties about personal identity. In a situation where one is different from everyone else, one looks at oneself much more closely than ever before. In the loneliness of a new and different group of people and in a situation where the familiar ways of doing and feeling do not seem right, one begins to wonder what sort of person he really is: 'If I can't be my old familiar self, what kind of person will I become?' (Guthrie, 1975, p. 100)

In the ensuing period of insecurity, there are very few clues to which the individual can turn for guidance. The old roles are not discernable, the old in-groups have been left behind, even the familiar guiding force, the language, is no longer available in the way it once was. For sojourners who are suddenly forced to look at themselves more closely than ever before, the invisibility of any sort of social framework to which they might turn for support will certainly be frightening. 
The concepts discussed up to this point have been chosen to illustrate how deeply intertwined language and culture are. So closely connected are the two that an identity, the linguistic identity, becomes apparent. Guiora and his colleagues (1972) discuss this identity in terms of the way people sound when they speak. Language is used in both verbal and non-verbal form to reduce uncertainty in new situations but if the linguistic messages are unclear or are misinterpreted then uncertainty is compounded. Language is also used to delineate social roles and membership in social groups. This use of language ties back to Guiora's discussion of language and identity for language is used to signify adhesion to or rejection of specific groups. The reader should bear in mind the role language plays in each of these areas while reading the next chapter. These roles carry implications for culture shock training which are integral to the argument about to be built that sojourners' native languages play an important role in their experience of culture shock. As was stated at the beginning of this paper, it is necessary to view the existing paradigm of culture shock with careful scrutiny. The reason for looking so closely at the paradigm is to find a way of incorporating the role of the native language so that sojourners can better understand, and be prepared for, their encounters with culture shock.

Before turning to a focused discussion of language though, it is necessary to focus briefly on the notion of identity. As was mentioned in the Definition of Terms, there is a significant amount of psychological connotation carried with such words as identity and it would not be appropriate to fail to foray into the world of psychology for some explanation of the notion. This foray is also crucial because, as was shown in Chapter III, the culture shock researchers surveyed show a tendency to class culture shock within the realm of the psychological. Too often the issues discussed within this realm conjure images of mental illness (Foster, 1971), when, in fact, what may actually be implied is a productive, creative experience (Adler, 1975; Asante \& Barnes, 1989). Culture shock 
research appears to be moving more into the realm of the positive which is a very viable direction for it to be taking and one which should be supported and encouraged. The fact that the research is moving into a new realm makes it appropriate, at this point, to add on to the existing model. Those authors (Adler, 1975; Adler, 1987; Asante \& Barnes, 1989; Weaver, 1986) who contend that culture shock is an experience to be anticipated without fear are the individuals whose arguments promise to smooth the passage of sojourners between cultures. Allowing culture shock to remain in the annals of mental illness could prove to be a serious barrier to this movement.

In order to further the argument that classifying culture shock within the realm of the psychological need not be negative, I would like to present the ideas of the psychologist Baumeister (1986) who devoted an entire book to the subject of identity, more specifically, to identity crisis. I think the reader will agree that his description of people in identity crisis is remarkably similar to the description of people in culture shock. Furthermore, his discussion of identity crisis is very positive. He goes so far as to say that identity crisis, although first used to describe aberrant behavior "became used to refer to formative struggles of 'normal' persons" (Baumeister, 1986, p. 198).

\section{IDENTITY CRISIS}

Identity crisis, like personality and ego which were discussed in the Definition of Terms at the beginning of this paper, is a phrase with which most people are familiar and which conjures up very clear images in the minds of people who hear it. Erikson is credited with the coinage of the term and it may be concluded "that identity problems must have been widespread in our society by the time he coined the term [which would explain] why society seized on the term. .. and began using it in many contexts" (Baumeister, 1986, p. 198). Yet identity crisis has not been thoroughly studied and is not at all clearly understood. Baumeister credits this lack of understanding to the possibility 
that "all identity crises do not have the same kind of process" (p. 199). The similarity between culture shock and identity crisis begins at this point. Perhaps one reason why culture shock is not well-understood is because it happens differently to different people at different times.

Following the lead of Habermas (1973) who investigated crisis at the level of large social systems, Baumeister draws a distinction between two different kinds of identity crisis -- identity deficit and identity conflict. Although some parallels exist between culture shock and identity conflict, they are far outweighed by the similarities between culture shock and identity deficit. "Identity deficit ... refers to the inadequately defined self, characterized by a lack of commitment to goals and values" (p. 199). When in culture shock, sojourners find that their selves are no longer clearly defined (as was discussed in the section on Social Psychology) and they find that they can no longer be as committed to previous goals and values (as was discussed under the guise of beliefs and attitudes in the Intercultural Communication section above) as they had been prior to their arrival in the new environment.

Before continuing this line of argument, it is necessary to acknowledge that most of the work in the area of identity crisis has been done with adolescent males. Surprisingly little work has been done on females of any age. While adolescent males do not comprise the subject group of this paper, Baumeister's ideas are nonetheless applicable for the following reason. In a later discussion, Baumeister compares the experiences of adolescent males with that of middle-aged men who are in the throes of mid-life crisis. Following Baumeister's example of drawing comparisons across boundaries of age and experience, and in light of the remarkable similarities between the two states which I am about to present, it is acceptable to recommend that the experience of culture shock, although it is experienced by men and women of all ages, be viewed as a type of identity crisis as well. After all, central to the culture shock experience is a 
questioning of who one is and what one is about. Certainly this is what Baumeister describes as "identity deficit [where] the problem is having not enough identity" (p. 199). In culture shock the individual experiences a lack of identity within the new culture.

Crisis stems from the conflict of contradictory impulses. In the case of the adolescent male, he feels pulled between the desire to remain a child under the protective wings of his parents and the desire to abandon his parents in favor of entering into adulthood. Culture shock sufferers feel pulled between maintaining the beliefs and attitudes they brought with them from their own cultures and accepting the beliefs and attitudes of the new culture. Inherent in both of these struggles is some attraction the strugglers feel for what what they have not yet achieved -- for the young man, adulthood, and for sojourners, adaptation. Also crucial though is the need to retain something of what the strugglers possess at the onset of struggle -- for the young man, his relationship with his parents, for sojourners, their national identity. If the desire to enter the new world or to retain part of the old is not strong enough, then no struggle will ensue. As Baumeister (1986) states, "if you reject the entire system you have no crisis -- you have nothing. A crisis occurs when you reject, or at least put on trial, a large enough part of the system that the system may have to change fundamentally" (p. 205). In culture shock, individuals are forced to put their beliefs and attitudes, in short their identities, on trial.

A question that consistently arises in culture shock literature is Why? Why does it seem to be inevitable that an individual experience culture shock no matter what sort of preparation occurs prior to departure? Baumeister asks a similar question -- "Why does [identity crisis] start at some particular point in adolescence instead of much earlier or later?" (p. 205). He recommends two answers. One he garners from the area of cognitive development. Adolescence is a time of heightened self-consciousness. This "increased ability to reflect on oneself and to imagine how one is perceived by others probably increases the ability to exert control over oneself" (p. 205). The adolescent suddenly 
finds himself able to make decisions independently of his parents about how he wants to live his life. The ideals and values he had learned from his parents and had taken for granted are called into question. According to Baumeister's (1986) discussion, the adolescent male rejects the goals and values of his parents during puberty. He realizes that he may very well decide to discard them in favor of a different set of ideals and values. Such a rejection marks an assertion of the young man's self but also leaves him without the familiar supports that he has grown up with, hence the crisis. Suddenly he is left to develop his own way. In culture shock, the individual is no longer surrounded by the comfortable traditions and values of the home culture and at the same time the individual is forced to call them into question for what is probably the first time.

The case of sojourners is surprisingly similar. As was discussed in the last chapter, entry into a new culture precipitates extreme self-consciousness. Just as teenagers become extremely self-conscious when they realize that they are gaining control over their lives, sojourners become more introspective when they recognize the existence of other ways of doing and seeing things than they have heretofore been familiar with. But differently from teenagers who begin to have an understanding of how others perceive them, the crisis suffered by sojourners is exacerbated by the fact that they cannot begin to perceive how host nationals view them. Already in a precarious state of self-consciousness, sojourners feel threatened by the fact that they cannot evaluate their own behavior in the new culture, and may become hostile to their hosts (Stage 2 of culture shock in Oberg's model, 1960).

A second reason Baumeister suggests to explain the timing of identity crisis is the sudden demand to choose which is placed on teens. Children are not required to make decisions; their parents have that responsibility. But adolescents must grapple with the notion that with the freedoms that adulthood promises, 
comes the necessity to make commitments and to choose between incompatible childhood dreams. The adolescent in crisis

has to give up some of his or her options for future identities--has to abandon some potentialities. That hurts. Why are adolescents sometimes reluctant to commit themselves? A major part of this reluctance could be that such commitments entail letting go of other possibilities. (p. 206)

Sojourners who experience culture shock have to give up some preconceptions about their native cultures which must hurt equally as much. While in the second stage of culture shock, sojourners begin to feel irritated by pretty much everything the host nationals do. Eventually nothing seems to make sense and sojourners find that they must question the ways their hosts have of living. Such questioning inevitably leads to questioning the sojourners' ways of doing things. Much in the same way that the teenager realizes the values of his parents may not be the only values, sojourners realize that the beliefs and attitudes they have always held may not represent the only legitimate ways of looking at life. This questioning of even the smallest aspects of life that had been taken for granted opens the sojourner to the possibility of understanding the new culture but not without expense. For in acknowledging the possibility that the hosts' ways of living may be equally legitimate, sojourners must give up some preconceptions about their native cultures. Baumeister mentions Levinson (1978) who describes "the male mid-life crisis as a failure of the goals and values that have sustained the man" (p. 208). The mid-life crisis ensues when the man's dream of promotion and status does not materialize as he had envisioned it. This image nicely parallels the inevitable disappointment of student sojourners who often create paradise-like preconceptions of their host countries, only to find something less than they had imagined.

The parallels between identity deficit crisis and culture shock are, so far, striking. An even more convincing argument for the inclusion of culture shock in the rubric of identity crisis is found in Baumeister's (1986) description of the subjective experience of 
identity crisis. Although the researchers Baumeister cites were investigating identity crisis, the recurrent themes of identity deficit coincide with those described by researchers of culture shock. In Table II the symptoms of identity crisis and culture shock have been arranged for comparison.

Despite the fact that identity crisis "is listed in the Diagnostic and Statistical Manual of Mental Disorders, Volume 3 by the American Psychiatric Association [it is regarded by many] as a valuable and desirable experience. [Among these are] Erikson (1968) [who] felt that adolescent identity crises were essential to proper growth and

TABLE II

COMPARISON OF IDENTITY CRISIS AND CULTURE SHOCK SYMPTOMS

\begin{tabular}{|l|l|}
\hline \multicolumn{1}{|c|}{ IDENTITY CRISIS } & \multicolumn{1}{|c|}{ CULTURE SHOCK } \\
\hline $\begin{array}{l}\text { Vacillating commitment and confusion } \\
\text { about values (Newman \& Newman, 1978) }\end{array}$ & $\begin{array}{l}\text { Confusion in role, values, feelings, self- } \\
\text { identity (Adler, 1975; Furnham, 1988) }\end{array}$ \\
\hline $\begin{array}{l}\text { Feelings of emptiness and of vagueness } \\
\text { (Marcia, 1966; Rubins, 1968; Schaefer, } \\
\text { 1973) }\end{array}$ & $\begin{array}{l}\text { Withdrawal, sense of alienation (Barna, } \\
\text { 1983; Bennett, 1977) }\end{array}$ \\
\hline $\begin{array}{l}\text { Preoccupation with great, seemingly } \\
\text { unresolvable questions (Marcia, 1966) }\end{array}$ & $\begin{array}{l}\text { Feelings that everything is going wrong, } \\
\text { helplessness (Adler, 1975; Foster, 1971) }\end{array}$ \\
\hline $\begin{array}{l}\text { Apparent detachment from or loss of } \\
\text { interest in the mundane issues and concerns } \\
\text { of everyday life (Bickford, 1971) }\end{array}$ & $\begin{array}{l}\text { Retreat into enclaves of sojourners from } \\
\text { home country (David, 1971) }\end{array}$ \\
\hline Anxiety (Marcia, 1967) & $\begin{array}{l}\text { Furnham, 1988; Harris, 1976; Oberg, } \\
\text { 1960) }\end{array}$ \\
\hline $\begin{array}{l}\text { Self-consciousness, rumination about the } \\
\text { meanings and implications of one's actions, } \\
\text { "overexamined life" (Keniston, 1965) }\end{array}$ & Defensiveness (Bennett, unpublished) \\
\hline $\begin{array}{l}\text { Feelings of confusion, bewilderment, } \\
\text { occasional discouragement, generalized } \\
\text { malaise (Bickford, 1971; Marcia, 1967; } \\
\text { Schenkel \& Marcia, 1972) }\end{array}$ & $\begin{array}{l}\text { Irritability, depression, general annoyance } \\
\text { (Adler, 1975; Bennett, 1977, Foster, 1971) }\end{array}$ \\
\hline $\begin{array}{l}\text { Dissatisfaction and hostility toward } \\
\text { authority } \\
\text { (Bourne, 1978; Marcia, 1966, 1967; Marcia } \\
\text { \& Friedman, 1970; Podd, Marcia \& Rubin, } \\
\text { 1970; Schafer, 1973; Schenkel \& Marcia, } \\
\text { 1972) }\end{array}$ & $\begin{array}{l}\text { Hostility toward and rejection of host } \\
\text { culture (Adler, 1975; David, 1971; }\end{array}$ \\
\hline
\end{tabular}

Note: Information in column one is adapted from Identity (pp. 212-213) by R.F.

Baumeister, 1986, Oxford: Oxford University Press. 
development. Blos (1962) observed that such a crisis strengthens the ego" (Baumeister, 1986, p. 227-228). As is stated in the introduction to this section, identity crisis has evolved from a term used to describe aberrant behavior, to a term "used to refer to formative struggles of "normal' persons" (Baumeister, 1986, p. 198). The key word in this description is formative which indicates that such crises are, or can be, potentially productive. This coincides with Adler's (1975) suggestion that culture shock be looked at, not as a negative experience, rather as a creative experience from which the individual emerges a more complete, well-rounded being. If culture shock truly may be looked at as a type of identity crisis and if, as Baumeister contends, "the evidence is more consistent with the notion that identity-deficit crises are good (rather than bad) for you" (p. 228), then it must be deduced that culture shock also has more positive creative potential than it has been credited with.

From a vast array of relevant information, I have chosen three areas in which to concentrate the attention of my readers. Two of these areas, intercultural communication and social psychology have been discussed in such a way as to familiarize the reader with notions I will develop in the remainder of this paper. From intercultural communication I have chosen the theory of uncertainty reduction. My experience, and that of many other exchange students, has convinced me that the reduction of uncertainty is the primary goal of initial encounters with members of the host culture. The way most student sojourners choose to reduce uncertainty is by involving their hosts, the approach described by Gudykunst and Ting-Toomey (1984) as interactive.

In the area of social psychology I concentrated on social group theory. Individuals retain membership in many different groups simultaneously; students are peculiar in that they often juggle the roles of child, employee, parent, and student at one time in addition to the various roles they are required to fill as members of their society. When these individuals enter new cultures, they must relearn what their roles are and how 
they are to fit into the new society. The roles that had been comfortable at home are suddenly called into question. They are given access to their new roles by way of communicating with their hosts and in order to do so must learn how to use the hosts' language effectively. There is significantly more to this effective use of language than mere learning of the language, yet this issue is not addressed in culture shock literature.

Finally, I devoted a section of this chapter to psychology in an effort to better understand the principles of identity formation and development. What I found was a striking parallel between Baumeister's (1986) description of the symptoms of identity crisis and the symptoms described in Chapter II of culture shock. I encourage the development of this parallel for the purpose of changing attitudes about culture shock from anxiety to anticipation.

Each of these areas is closely tied to the exploration of culture shock and in each area one can find explanations for some aspect of the culture shock experience. Language figures prominently in the task of intercultural communication, in the development and maintenance of social groups and roles, and in the formation of identity. Yet language and the identity which individuals develop in relation to their native languages do not have prominent places in current discussions of culture shock. This ought to change. In the next chapter, I will discuss exactly how important language and the linguistic identity are to further exploration of the culture shock question. 


\section{CHAPTER IV}

\section{LINGUISTIC IDENTITY: INTEGRATING LANGUAGE INTO THE CULTURE SHOCK PARADIGM}

Language is a prostitute queen who descends and rises to all rôles, disguises herself, arrays herself in fine apparel, hides her head and effaces herself; an advocate who has an answer for everything, who has always foreseen everything, and who assumes a thousand forms in order to be right. (George Sand, 1978, p. 94)

In Chapter I, I discussed my experience of culture shock. While the tangible aspects of the new culture were curious to me, it was the intangible which was really disturbing. I found that disturbance focused in my apparent inability to communicate my SELF to the people I was meeting despite my fluency in their language. It seemed that the people were getting to know a rather serious young woman who had trouble loosening up and making light of issues. This character ran contrary to what I knew of myself. What was it that was creating the inaccurate impression of me in the eyes of my new acquaintances? How were they getting to know me? In a situation where we shared little background information, we were forced to rely on only one resource, language, to learn about each other.

Yet this resource, language, is only minimally represented in the descriptions of culture shock presented in Chapter II. More importantly, the intimate link between language and culture, linguistic identity, is completely neglected in those descriptions. My experience of having to rely on language as my sole resource to learn about the new environment in which I found myself and the fact that language is a feature shared by each of the areas discussed in Chapter III indicates that the inclusion of language in the culture shock paradigm may provide the key to understanding why every sojourner, regardless of 
preparation, suffers to some extent from culture shock. For the remainder of this chapter, I will discuss how important language is to human interaction and to the development of the human environment. I will also make the claim that linguistic identity, precisely because of its importance, must be included in the culture shock paradigm.

One topic to which I have repeatedly referred in this paper is identity. While abroad, I often posed the question Why don't I feel like myself in Germany? More specifically, I wondered why I did not feel like I could be myself in German. The problem was not in being; I knew who I was and I was confident in my understanding of myself. The problem was in the conveyance of that being. Until I went to Germany I had relied on language to convey who I was to new people. Within the confines of a new cultural setting and dependent upon a new language, language no longer did the job I had come to rely on. What I have come to understand though, is that language did not really fail me. Rather, I had not yet formed an identity, an understanding of myself, within the structure of the German language such that I was capable of successfully conveying my SELF. This linguistic identity is central to the following discussion.

Language is the device to which we turn when we want to share our inner beings with one another. It is an extremely complex device and is not easy to pin down for analysis. One researcher who attempted to understand language, and its relationship to culture, was Sapir. He is well-known for his analyses of language and his attempts at sorting out this complex phenomenon are still frequently cited in linguistic and anthropological research. Sapir (1929) wrote that worlds are shaped by the individuals who inhabit them through the languages they speak. He called language a "guide to 'social reality'" (p. 162) and went on to declare that

It is quite an illusion to imagine that one adjusts to reality essentially without the use of language and that language is merely an incidental means of solving specific problems of communication or reflection. The fact of the matter is that the 'real world' is to a large extent unconsciously built up on the language habits of the group. No two languages are ever sufficiently 
similar to be considered as representing the same social reality. The worlds in which different societies live are distinct worlds, not merely the same world with different labels attached [italics added]. (Sapir, 1929, p. 162)

This last statement is vital to the argument that language is central to the experience of culture shock. If our world is built up on the language habits of the society from which we come, than it is no wonder that we are surprised, shocked even, to find that a society which speaks a different language actually exists in a different world. Wardhaugh (1992) echoes Sapir's ideas indicating that

language provides a screen or filter to reality. It determines how speakers perceive and organize the world around them, both the natural world and the social world. Consequently, the language you speak helps to form your world view. It defines your experience for you; you do not use it simply to report that experience. It is not neutral but gets in the way, imposing habits of both looking and thinking. (p. 221)

If language is as "in the way" as Wardhaugh and Sapir contend, then it is easier to understand my experience of culture shock. The ME who I am in my native language was stifled in the culture of my second language because I had not yet learned how to express that me within the framework of a different culture and language. My guide to social reality did not apply to the new society in which I found myself because my guide was American English. The guide of my hosts was not only German; it was the Swabian dialect of German. Neither did my linguistic filter (Wardhaugh, 1992, see above citation) function properly. The picture people were getting of me was distorted and I can only begin to imagine how inaccurate my impression of them was!

Samovar and Porter (1991) address the complexity of language from yet another angle. "Words," they maintain, "are abstractions of our realities" (p. 146). They succeed as representative symbols only as long as the individuals using them share enough common background as to ensure the meaning of the words. Therefore it cannot be assumed that the way one culture has named an object and all of the nuances that are carried by that name will automatically apply to the same object in another culture. For when common background is absent, as in the case of the sojourning experience, the process of 
abstraction by which we arrive at word meaning is complicated. As an example, Samovar and Porter (1991) use the word dog which in U.S. American society conjures the image of a small, four-legged creature with a tail and a long nose which is kept as a house pet. The phrase which leaps to many minds in this society when the word dog is heard is man's best friend. But as Samovar and Porter point out, the word for dog conjures up a very different, and to U.S. American minds a very disturbing, image for the Vietnamese. In Vietnam dogs are considered a gastronomic delicacy. One would probably not consider keeping a dog as a house pet any more than a U.S. American would consider keeping a pig or a cow as a pet.

This is a simple example, but it proves that words are more than simple labels which can be applied universally to similar referents with the same meaning resulting. By extension, language "is much more than a mere set of word symbols governed by rules. It is far more complex than that because the language symbols are only abstractions of the real states of our being and, as such, are inadequate substitutes" (Samovar and Porter, 1991, p. 148).

To briefly restate my argument in the words of another researcher, "identity occurs through learning to interpret behavior, rather than simply learning to understand one's body. The requirements of language. . . lead us from behavior to identity" (Baumeister, 1986, p. 178). Infants discover their bodies before they acquire language. It is only through the acquisition of language that they gain access to the interpretation of their own behaviors as well as those of others which they witness. For individuals who cannot acquire language, or who do so in a different way, access to their environment is temporarily impeded. Their experience is similar to that of sojourners in that the access sojourners have to the environment of their hosts is also temporarily impeded. Sojourners who do not speak their hosts' language well must strive to make their needs known by way of highly simplified language. Their access to understanding is impeded by their inability 
to formulate precise questions as well as their inability to understand sufficiently the answers they receive. If they are persistent and do not give up, and if both sojourners and hosts are patient, then, like children when they first begin to acquire language, sojourners will find that their skills improve very rapidly. The results of sojourner persistence have a snowball effect -- a small piece of acquired knowledge provides courage for more exploration which, in turn, leads to more knowledge. ... This continuum progresses much in the same way as it does for children who become teens who eventually become adults who, even having reached adulthood, are constantly learning and acquiring new knowledge.

Sojourners who enter new cultures are usually aware of their identities within a familiar environment. Students are usually sure of what is expected of them in each of their many roles - child, parent, employee, student. Although they may not be entirely selfconfident, the demands of the environment are clearly expressed. This awareness of self and confidence in what is demanded of that self must necessarily change when sojourners enter a new culture.

Despite predeparture orientation, and other preparation, students receive a shock upon entering new cultures because regardless of the security of their identity at home, within the parameters of the new culture their identity is shaken. As I discussed in Chapter III, even familiar roles may manifest themselves in different forms. The shock is rooted in a certain naiveté. No matter how often sojourners are told The culture you are about to enter is different from what you know, they can never sufficiently anticipate the scope of that difference until they are immersed within the new culture. Until sojourners reach that point at which they are surrounded, they maintain the belief that all people are basically similar, therefore how different can a new culture be? This is a tool of survival. Who could freely admit that a world might exist in which they are stripped of their familiar identity? By assuming that basic similarity, indeed by denying the possibility of the 
fundamental difference of various cultures, human beings maintain a firm grasp on who they are.

Upon entering a new culture sojourners are shocked to find that the identities they have brought with them into their new environment do not necessarily fit into that setting. Sojourners do not know how they are supposed to fit in any more than their hosts understand where to place them. The reader should recall my discussion in Chapter III of social roles, social groups and social identity. There exists, as is stated in that chapter, a period of time during which sojourners lack identity in the host culture. Until sojourners are able to determine where social group delineations fall and where they stand in relation to those lines, sojourners must acknowledge the fact that they will be viewed by their hosts as outsiders and that their identities will be temporarily defined by their hosts based on stereotypes. Their hosts do not know them and s ojourners' facility with the new language may seriously impede their ability to communicate who they are and what they are about. Sojourners are effectively rendered infantile. Many sojourners complain that they feel like children when they interact with their hosts. They know what their needs are, but they do not know how to communicate them to their hosts effectively or appropriately because they are not fluent in their hosts' language and do not possess the sociocultural competence necessary to wade through in-group/out-group delineations or through social hierarchy structures. Sojourners know how they feel and they know that they are thoughtful, intelligent beings, but, as my friend Michelle explains it, "they feel like they come across to their hosts as babbling idiots." I think all sojourners can relate to the scenario of having uttered a carefully prepared sentence which they are sure is grammatically correct, socially proper, and skillfully executed only to be met with a blank stare of utter incomprehension, or worse yet, that patronizing nod of patience followed by an expectant stare which betrays the hosts' assumption that the sojourner will instantaneously reformulate the statement to something that is comprehensible. Sojourners, 
at that point, may frequently be so disappointed and frustrated that further attempts become progressively simple and, to the sojourner as well as to the host, more confused and babbling. As was mentioned in the preface, those sojourners who try to win the favor of their hosts by employing humor find their attempts misinterpreted, or, worse yet, simply disregarded as errors. Try as they may to be creative with whatever language skills they have, sojourners will often find themselves forced to rely on the simplest of constructions to communicate their ideas without risking being misunderstood. University honors students and successful executives often lose the laurels they have come to take for granted and find that they must struggle to prove themselves to hosts who tend, or so it appears to the sojourner, to be mercilessly impatient. It is no wonder that sojourners enter the second stage of culture shock (Oberg, 1960) in which they come to feel hostile or aggressive toward their hosts.

As time passes though, sojourners will find that they slowly begin to gain access to the new culture. Just as children learn the proper names for things and how to string those names together, so sojourners become linguistically agile. They find that as their language facility increases, their hosts begin to pay attention to them as individuals. In a study abroad situation like the one in which I participated, the local people, students and other inhabitants alike, get used to a constant flux of foreign students. The locals know that after nine months the foreign students will be replaced by a new batch and the nine month period is hardly deemed long enough to make the effort the get to know the individual sojourning students. The visiting students blend into the anonymous group of foreigners which ebbs and flows with the ending and subsequent new beginning of semesters. But as their linguistic dexterity increases, the visiting students' identities take shape and they will find that some people will take notice of them. They are taken seriously. Their ideas are listened to and are commented on. They find themselves communicating with their hosts; 
the messages they send are interpreted correctly and are effective. Eventually even their jokes will be laughed at and will no longer be patiently corrected.

It is important to note that identity development is a two-way affair. Not only must the individuals who are undergoing the identity crisis come to a new understanding of identity, also the people with whom they come in contact must recognize that new identity and accept it. This is the detail that confounds the experience of the sojourner. If sojourners could enter into a new culture and it did not matter whether or not their hosts recognized and accepted the old identity, then there would be no crisis. But it is crucial to the success of sojourners in new cultures that their hosts recognize an identity. Because the hosts cannot fully comprehend the scope of the sojourners' identities at home, they cannot simply accept that identity within the bounds of their own culture. It is the task of the sojourner to develop, and become comfortable with, a new identity. Once these new identities begin to take shape, sojourners will find, as children do, that their progress begins to gain momentum until they are hurtling through new lives. Unfortunate for the student sojourner is the fact that this headlong sprint into a new existence usually begins about three months before it is time to return home.

Thus far in this chapter I have discussed the centrality of language in the interaction of human beings with one another. Language plays an extremely important role in the area of social role definition, social group delineation, and social identity each of which must be learned before one can successfully participate in another culture. Byram (1989) states that language and the varieties thereof -- dialect or sociolect -- are

overt signs of cultural identity which people meet daily in their lives. Individuals use language varieties with varying degrees of self-awareness to signal their social identity, often 'accommodating' their language to the requirements of situations and interlocutors. (p. 40) 
If, as Byram contends, "language pre-eminently embodies the values and meanings of a culture, refers to cultural artifacts and signals people's cultural identity" (p. 40), then it must play a significant role in the experience of a new culture.

But what about sojourners who arrive in their host countries with more than a rudimentary knowledge of the new language? I went to Germany with ten years of training in the German language and still I experienced an identity crisis. Why, when I had a firm grasp of their language, was it so hard for me to introduce the Germans to who I was? My education did not provide me with the sort of access I anticipated would accompany my fluency. The problem is one that has been discussed most extensively by Krashen (1980; Scarcella \& Krashen, 1981). Krashen has devoted a good deal of time to researching the difference between language learning and language acquistion. Learning, according to Krashen, is what takes place in the classroom. The primary focus of language learning is "error correction and the presentaton of explicit rules" (Krashen, 1981, p. 2). Language acquisition on the other hand, is most easily understood as being what happens when children pick up their native languages. "It requires meaningful interactions. . . in which speakers are not concerned with the form of their utterances but with the messages they are conveying and understanding" (Krashen, 1981, p. 1). Learned rules can only really be used to monitor what has been acquired. While Krashen feels that acquisition can, indeed should, become the primary focus of second language instruction, the focus of instruction remains on the presentation of rules. Consequently, the language one learns in the classroom is not the same as the language which is used by those who speak it natively. The learned language has been abstracted away from its culture and is presented to students in a purified, grammatical form which can be taught scientifically (Byram, 1989). The student learns individual words and grammatical structures and how they can be manipulated. The words are assigned values, (noun, verb, preposition) and are plugged into the learned grammatical structures much in the same way that numbers are plugged into 
mathematical formulas. The end result is the ability to form and to understand grammatically correct sentences. This is admittedly a harsh example of what goes on in language classrooms and the picture is changing but that change is occuring very slowly. In any case, no native speaker of a language speaks that language like it is presented in textbooks to students who learn it as a foreign language. Ironically, the language which facilitates reflective thought, the language one acquires as a child from one's parents, is itself not reflective, rather it is completely spontaneous. The native speaker does not contemplate grammatical structures and knowingly scan a learned lexicon before uttering a sentence. But the student of language does exactly this. The language I brought from the classroom to the culture was calculated -- it was learned. I constantly reflected before speaking. It was not free-flowing as was the language of those around me who had grown up speaking German. They had acquired their language skills and spoke without contemplating structures or endings. Additionally, the language I had learned was the unspoken high German of literature and newspapers. All of the people I met were speaking either regional dialects or a vernacular which was littered with colloquialisms to which I had never been introduced in the classroom. What I found was that my years of education speeded the process of my assimilation but by no means did they ensure immediate access to the German culture as I had hoped they would -- indeed as I had been led to believe they would by the literature on culture shock which ensured that language proficiency would smooth the culture shock curve considerably. I had considered myself to be a fluent speaker of German but what I found was that although I had internalized the rules of German grammar, I had not acquired the ability to speak comfortably. As Krashen (1981) notes, "fluency in second language performance is due to what we have acquired, not what we have learned" (p. 99).

The absence of language, specifically of linguistic identity, from the culture shock paradigm explains why culture shock training has not been as effective as might be desired. 
Language plays a crucial role in the ability of human beings to communicate with each other successfully and this role is taken for granted. Sojourners must be encouraged to understand that the languages they speak as children help form their visions of the world. If they are able to even begin to understand this, then it will be easier for them to understand why they have such trouble adjusting to new environments in which new languages are spoken. Sojourners must also be prepared for undergoing an identity crisis in the course of their sojourn because the new language they will have to speak will force them to view the world differently. Even if they have learned to speak the language of the new culture, until they have the opportunity to develop a linguistic identity within that culture they will feel out of place. This knowledge should not be overwhelming or intimidating. Patient sojourners who have been briefed about the impending crisis will be ready to grapple with it and will usually emerge having achieved a greater understanding of themselves. They will learn to communicate their wants, needs and ideas in a new way and will often come to know aspects of themselves which had previously gone unnoticed. Adding these dimensions to the culture shock paradigm will ensure more effective training strategies and more successful cross-cultural sojourning experiences. 


\section{CHAPTER V}

\section{TOWARDS THE DEMYSTIFICATION OF CULTURE SHOCK}

It is not so much the culture that must be the focus of training as it is the demystification of the shock effect. (M.K. Asante \& A. Barnes, 1989, p.104)

Culture shock is well known as an inescapable part of the study abroad experience. First named and defined by Oberg, this experience of the sojourner is dreaded by every student who traverses the ocean (in whatever direction) in search of the experience of another culture. As well known as culture shock is, there is no clear cut definition of it, neither has anyone found a sure way to avoid it. What I have argued in this thesis is that culture shock remains a mystery because a crucial aspect of the sojourner's character has been overlooked - the linguistic identity. In the review of culture shock research, many views were presented which vary in their description of culture shock from a malady like the common cold to an extreme psychological reaction to new influences. Sojourners are encouraged to learn the language of the cultures into which they are traversing, but no one has adequately addressed the role sojourners' native languages plays in their inevitable experience of culture shock.

Efforts to change this pattern and to begin addressing the role of the linguistic identity in culture shock must occur in three areas. There are implications for language educators, for cross-cultural trainers and for further research in the area of culture shock. In this final chapter, I will discuss implications in the first two areas and will then present an idea for future research which I had hoped to carry out as part of this thesis project. I have been unable to do so due to a lack of funding, but I hope in the near future to see my ideas 
to fruition. Before turning to a discussion of the implications though, I will provide the reader with a summary of each of the preceding chapters so as to refocus attention on the crucial points of each.

\section{REVIEW}

\section{Chapter I: Introduction}

In the first chapter I discussed my experience of culture shock and explained how it differed from what I had expected to encounter. I expected to be disturbed by the tangible aspects of the new society - foods, smells, sights. What I actually found more disturbing though, were the intangibles. I found that, despite my fluency with the German language, I had a particularly difficult time making myself understood in German company. More complicated still was the task of introducing myself to people. No matter how hard I tried to enable people to know me as people at home knew me, I constantly felt that they were getting to know someone else, someone with whom I was not familiar. I found, upon confessing these frustrations to friends, that my feelings were shared by most, if not by all of them. The question which plagued me was If so many of us are experiencing this, why is it not discussed more directly in the literature we were given? My goal in writing this thesis has been to explore this question in such a way as to encourage further exploration and the demystification of culture shock, primarily by way of including the native language, in the form of the language identity, in the culture shock paradigm.

\section{Chapter II: Culture Shock - The Existing Paradigm}

Chapter II consists of a review of the existing literature on culture shock from the inception of the term by Oberg in 1960 to Weaver's (1986) more modern and less medical discussion. In this chapter I illustrated that our understanding of the sojourner's malady has undergone significant transformation in the last thirty years - what was once viewed as a negative, disruptive psychological ailment has come to be looked upon as a creative 
experience, perhaps even a normal part of the developmental process. Oberg's focus is on the tangible. He discusses the disorienting nature of new sights, smells, sounds and the confusion that results from being deprived of familiar cues. While Oberg's discussion seems superficial, in hindsight it is invaluable. His four stages are still consistently referred to in predeparture literature and have provided the basis from which all future discussions of culture shock have originated. Oberg's description has also served the indispensable purpose of opening the discussion of culture shock and provided a first definition thereby establishing a foundation from which future researchers were able to depart.

One such departure was made by Adler (1975) whose focus is on the personal growth which evolves out of a successful grappling with the loss of that which is familiar. Adler is one of the first culture shock researchers to acknowledge that culture shock may very well have positive results. His five stages of culture shock form a curve which closely traces Oberg's U-curve, but Adler's description of culture shock includes a discussion of how struggle can strengthen an individuals' confidence and sense of self. In a later article, Adler (1982) delves deeper into the realm of the psychological, declaring that "cultural identity. . . is a fundamental symbol of a person's identity" (p. 26). The culture in which an individual is born has a tremendous influence on that individual's development.

The final researcher discussed in Chapter II is Weaver whose paper marks a radical departure from Oberg. Weaver's focus is on the creative, not at all on the destructive or debilitating and he insists that the growth potential of an individual who has experienced culture shock is great.

While the evolution of culture shock understanding is impressive, a key element of cultural identity has been neglected. Both Adler and Weaver discuss cultural identity, but neither one mentions linguistic identity. Indeed no one mentions linguistic identity. This term refers to the identity one develops relative to one's native language - the language one learns as a child. At the end of Chapter II I point out the fact that this linguistic identity is 
overlooked in all discussions of culture shock and ask the reader to bear in mind this notion of identity when reading the third chapter.

\section{Chapter III: Aspects of Culture Shock as Seen From Three Scientific Disciplines}

The third chapter of a thesis is traditionally the chapter in which the research methods and tests are described in detail. Because this is not a thesis based on empirical research though, I departed from traditional form and presented instead an exploration into three academic disciplines, intercultural communication, social psychology, and psychology, in an effort to shed light on the reason why culture shock impacts all sojourners regardless of preparation.

At the beginning of this chapter, a few pages are devoted to the research of Guiora whose construct, the language ego, precipitated my own research. Guiora's research has focused on adult second language acquisition and on the role personality plays in the success thereof. He and his colleagues (Guiora, Brannon \& Dull, 1971) have determined that empathy plays an important, and potentially significant, role in the ability of adults to learn pronunciation at least, if not all aspects of a second language. They hint at the link between language and personality. Their focus is on the actual production of sound, but they admit that task of learning a second language requires individuals to take on new identities. This declaration provides vital support to my own theory.

The first area into which I ventured for information on the relationship between language and culture shock was the branch of communication called intercultural communication. Because of the limited scope of this paper, I limited my exploration of this area to the theory of uncertainty reduction. Sojourners are forced to deal with multitudinous areas of uncertainty in their new environments and the theory posits that their chief goal is maximal reduction of that uncertainty. Gudykunst and Ting-Toomey (1988) suggest three strategies to employ toward the end of successfully reducing uncertainty. These strategies 
could provide a basis for new predeparture orientation sessions designed not only to familiarize potential sojourners with what culture shock is, but, more importantly, designed to empower sojourners to successfully cope with whatever manifestations of culture shock they encounter.

The first strategy is passive. Based on observation, the sojourner makes an informed assumption about the hosts unfamiliar behavior. The objective of this strategy is heightened awareness of differences. The second strategy is more interactive, involving the sojourner and sources outside the hosts' culture. The sojourner seeks explanations for curious behavior, beliefs and attitudes from informed sources. By employing the third strategy, the sojourner directly addresses the hosts for information about their culture. This strategy serves the dual purpose of informing the sojourner and increasing the hosts' awareness that what they consider to be usual and normal may, to others, seem quite extraordinary. It is informative strategies such as these, rather than description of symptoms which will most benefit sojourners.

My exploration of uncertainty reduction theory raised the question of social group membership which comprises one area of extreme uncertainty for sojourners. The task of deciphering where they fit in the new culture can be overwhelming. In the area Social Psychology I found information to the effect that each individual personality is comprised of a myriad of identities. As Collier and Thomas (1988) state, "personhood varies contextually. Not only does a primary identity emerge in a given context, but also identity is experienced at a variety of levels across situations" (p. 106).

One way we have of expressing these various identities, thereby delineating roles and social group boundaries, is by the way we speak. The examples given in the chapter were of teen slang and the medical and judicial jargons. These ways of speaking effectively exclude non-members of the particular groups. One need not only know procedures and behaviors to join the groups, one must also know the language. The implications of this 
type of insider/outsider demarcation is crucial to sojourners who, though they may have learned the language of their hosts, do not necessarily speak like insiders. Automatically they become outsiders and the ensuing relationship with their hosts is one of mutual mistrust (Tajfel, 1992). Most sojourners will overcome these feelings and will be able to carve out a niche for themselves in the new environment, but in the meantime, the period of insecurity during which social group boundaries and role definitions remain hazy can be particularly unsettling.

In the final section of Chapter III, attention was focused on Baumeister's discussion if identity crisis for the purpose of pointing out striking correlations between descriptions of identity crisis and culture shock. Like culture shock, the phrase identity crisis is used often in the vernacular and has become a buzz word with which most individuals are familiar. But because it is an experience which varies significantly from individual to individual, it is not at all fully understood (Baumeister, 1986). This lack of understanding is another point of similarity between identity crisis and culture shock.

The purpose of including this comparison was not to throw culture shock back into the realm of neurosis from which it has emerged, rather the contrary. By drawing parallels between identity crisis and culture shock I hope that future culture shock studies will follow the current path of identity crisis research which defines that crisis "as a valuable and desirable experience" (Baumeister, 1986, p. 227). If culture shock could be viewed in this positive light then perhaps it will no longer be seen as such a formidable force.

Although the three areas covered in Chapter III were only briefly attended to, a clear picture was presented of the complexity of culture shock and of the central role language plays in sojourners' ability to cope, recognition of self, and definition of roles and groups in the new environment. Having thus laid an interdisciplinary framework upon which to build my argument, I turned to the inclusion of language, specifically of the linguistic identity, in the culture shock paradigm. 


\section{Chapter IV: Language}

The basis for my argument that language be included in the culture shock paradigm is that sojourners use language to share their inner selves with their hosts and without language successful adaptation is very difficult. As Collier and Thomas (1988) state, "identities are formed, negotiated, modified, confirmed, and challenged through communication and contact with others" (p. 112). Without language there can be no contact and without contact neither sojoumer nor host is able to determine the identity of the other.

Additionally, language provides a guide to the social reality of sojourners so if they are not competent in the language of their hosts then they will not have adequate access to their culture. Without access to the guide provided by language, sojourners are forced to make simplistic attempts at communicating their wants, their needs, and their ideas. Perseverance will, in most cases, be rewarded with successful adaptation. But until that time, sojourners face a difficult struggle.

What remains then is a discussion of the implications this thesis holds for future culture shock experience and research. As is illustrated in Chapter II, culture shock has been traditionally regarded as a malady for which a cure must exist. Recently though, researchers are admitting the possibility that culture shock is unavoidable, indeed that it may actually be a desirable part of the sojourning experience. This tendency to view culture shock in a positive light is quite new and it must be supported. Efforts to change the old pattern and to begin addressing the role of the linguistic identity in culture shock must occur in two areas: the language classroom and predeparture orientation. These efforts will impact most immediately language educators and cross-cultural trainers whose task it should be to introduce sojourners to the idea of linguistic identity. Another area which will be impacted by the addition of language and linguistic identity to the culture shock paradigm is, of course, the area of research. Rather than specifically address which avenues must be 
traversed, I have decided to present the research proposal I submitted to Fulbright. I had planned to collect empirical data to back up the ideas I have presented here by accompanying a group of exchange students on their year abroad, but I was not funded. In the section that follows I will outline the implications for language educators and for cross cultural trainers and finally will present my research proposal.

\section{IMPLICATIONS OF THIS RESEARCH}

\section{Implications for Language Educators}

My attention to the task of language educators has been over-generalized thus far, but the generalizations were used to express the point that language educators have significantly more responsibilities today than they did thirty years ago. The days have past in which students were taught that words are merely labels - learn a word in a new language for a familiar object and if that word is applied in the new culture the same meaning will be understood. Today language educators are trying to integrate the teaching of culture with their teaching of language and are increasingly successful at their task. Still, many language educators were educated prior to the introduction of communicative language teaching strategies, and it is difficult for them to find the time to reeducate themselves. There is rarely time for teachers to "brush up" on all the details of the culture with which they may have had only peripheral contact themselves and that years ago. The difficult task of familiarizing themselves with the cultures of the languages they are teaching is especially so in the United States where other cultures are hardly within convenient reach for immersion purposes. But despite the physical isolation of the United States, there is ample opportunity for contact with other cultures.

Although language educators are trying to depart from the erroneous notions that words are just labels, the notion still exists in the minds of many beginning language students who often demand verbatim translations of new phrases and whine when teachers 
cannot provide them. The difficult task of convincing students that language is complex is compounded by the fact that students rarely encounter the nuances of words which prevent, for example, the word Gemütlichkeit ${ }^{2}$ from being translated into English. It is these nuances which are the very essence of language and provide the subtle distinctions which create different worlds around different languages.

The integration of cultural studies into language education will enable language educators to introduce students to such nuances of language as mentioned above and also to the notion of linguistic ego. Byram stresses the importance of integrating cultural studies, emphasizing that "to treat language quite independently of the culture to which it constantly refers cannot be justified; it disregards the nature of language" (1989, p. 41). He maintains that language and culture are inextricably bound up and that the relationship between the two is extremely complex. The intricacy of this relationship need not, however, be overwhelming to the language educator, for a comprehensive understanding of it is not the goal of language education. Rather, language educators should strive to sensitize their students to the fact that "language cannot be used without carrying meaning and referring beyond itself" (Byram, 1989, p. 41). An example of this may be found in the German language. American students of German learn that the word for friend is Freund(in). What they are not taught though, is that this word is reserved for very close friends. Casual friends are referred to as Bekannte, or acquaintances. This word carries no negative connotations, it simply refers to a relationship which is more distant than intimate. In a society like the German one, where social distance is strictly maintained by the use of formal and informal forms of address, such delineation of relationships is crucial. This is not the case in the United States where the use of first names among working colleagues is the rule rather than the exception and where a high rate of mobility requires friendships to be lost

${ }^{2}$ Gemütlichkeit - (approximately) the kind of comfort one finds in a low-ceilinged, dimly lit room where the family gathers on a cold winter evening around a crudely built, wooden table to enjoy a cup of hot spiced wine, each others company, and a warm fire. 
and reforged frequently. It is attention to details such as this one which will enable educators to point out that language is a cultural identity marker just as costume, food and social institutions are (Byram, 1989).

Byram (1989) also encourages language educators to expose their students to native speakers of the language the students are learning. Especially at the beginning level, "the linguistically and culturally dominant identity of the learners meeting a foreign language for the first time is likely to be their national language identity" (Byram, 1989, p. 96): in the case of U.S. American students, their U.S. Americanness. By bringing German students, for example, into a German classroom, U.S. American students would be introduced to the German identity from the point of view of an insider. The goal of such introductions is to give U.S. American students a chance to see how German is used by a German of their own age and to hear from an insider's point of view how it, and the German culture to which it is bound, differ from English.

Exercises in sensitization which would also introduce students to the culture in more intimate ways than are usually available in the United States entail the use of videos. Students might be shown videos of daily interactions or peculiar customs in the country of the language they are studying. At some crucial juncture in the video the instructor should stop it and ask students to predict the outcome of the interaction or the sense of some unfamiliar custom or habit they have just been watching. The successful prediction of the outcome is not crucial tothe success of the lesson, for students will be encouraged, regardless of their answers, to look critically at a scene and to use what knowledge theyhave of the culture to determine what is happening. This exercise can be varied by watching the tape without sound to the juncture, then with sound, finally all the way through with predictions at each stopping point.

Another video exercise works well with languages which employ formal and nonformal forms of address. Students should be asked to predict what relationship 
interlocutors in a video have based on the way they speak to each other. This type of exercise can be done without a picture so that students do not have visual clues to help them. After predicting the relationships, theyshould be shown the picture and then asked to evaluate their predictions. Again, the success or failure of the students' predictions is less important than the actual consideration of the scenario and prediction about the context for this process of deliberation will sensitize students. Such exercises will better enable them to engage the strategies discussed in Chapter III when they are sojourning abroad.

Although the specific aim of language educators is the teaching of language, the way this goal is achieved is undergoing revision. Language education will benefit from such focus shifts as are being recommended by Krashen. He suggests that language students will only acquire language if they are confronted with meaningful input. If this meaningful input is carefully presented, language educators could certainly awaken in their students an understanding of the roles language and culture play in their lives.

The inclusion of cultural identity and of linguistic identity in language teaching curricula will provide students "with the opportunity to acquire new competencies and to allow them to reflect upon their own culture and cultural competence" (Byram, 1989, p. 44). Such reflective capacity provides the first step toward successful sojourning experiences and is particularly important for U.S. American students who frequently believe the myth that they have no culture. One way for language educators to approach these topics is to draw comparisons between language structure and social structure. The expression of time provides a good example of how language reflects cultural habits. Time flies in English. In German it functions; in Spanish it walks and in French it marches. Students could be presented with such distinctions and then asked to research the cultures in which these languages are spoken to find possible correlations to how the native people live. Byram (1989) makes a very important note, namely that such introduction to culture in the classroom as was briefly discussed here "will not lead necessarily to a comprehensive 
view and experience of the whole culture, but this is not a disadvantage in curriculum development terms" (p. 97) for the goal of the language educator is simply introduction of the notions. Those students who actually have the opportunity to use their learned language in a native setting will hopefully recall what they learned about linguistic identity in their language classrooms and will be able to respond appropriately when forced to confront their own linguistic identities.

\section{Implications for Cross-cultural Trainers}

My intention in this project has been to demonstrate how language and linguistic identity are central to the experience of culture shock and to examine why neither language nor linguistic identity have played key roles in cross-cultural training intended to allay the effects of culture shock. I reviewed current literature on culture shock and presented a picture of culture shock as it is now illustrated. It is defined primarily as an illness which means there should be a cure, yet no cure has been found. Indeed I argue that none should be sought because culture shock, a type of identity crisis, is a creative experience of growth. Rather than preparing sojourners for combating culture shock, training should prepare sojourners to work with culture shock as a means of better understanding themselves and their cultures as well as the relationship between the two.

Cross-cultural trainers have more responsibilities than language teachers, for their job is specifically oriented to preparing sojourners for a journey abroad. The task of the cross-cultural trainer is to give sojourners the skills necessary for coping with their inevitable experience of culture shock. In this discussion I will focus specifically on those trainers who work with students who are about to sojourn abroad because students are the subjects of the research project I outline in the next section. In order to effectively prepare sojourners for a successful time abroad, cross-cultural trainers must demystify culture shock by drawing attention to cultural and linguistic identity, and they must arm sojourners with 
methods for coping in unforeseen situations. This is not what is happening in most predeparture orientations now and a number of researchers have discussed the drawbacks of traditional orientation practices. One major problem La Brack (1986) sees is that "the year abroad is seen. . . as a stage of development, almost as an activity which has a life span of its own which begins when the student enters the foreign milieu and ends with the return home" (p. 224). Little or no attention is paid to the far-reaching implications of such an excursion and students are not prepared ahead of time to approach this year abroad as an opportunity to learn a great deal about themselves and about their own cultures in addition to the obvious potential for learning about the culture in which they will sojourn. Weaver (1986) contends that many cross-cultural trainers devote far too much energy to catching and keeping the attention of their audiences. Certainly "students do not accurately know what to expect and are eager to get on with the trip, often treating orientation as an imposition or, at best, a preview of coming attractions" (La Brack, 1986, p. 224). But Weaver (1986) points out that extensive use of charts and graphs and flashy movies may lend the impression "that there is little pain involved in cross-cultural adjustment" (p. 132). This is very misleading.

The task of preparing sojourners is no simple one and it is made more difficult by the fact that most sojourners want "to have a simple formula for dealing with culture shock with concrete descriptions and directions" (Weaver, 1986, p. 123). Such cookbooks, as Weaver names them, for dealing with culture shock are not effective because "it is not possible for an orientation program to describe and explain every possible situation a student may be confronted with" (Winter, 1986, p. 331). This is true not only because of the nature of orientation programs, but also because culture shock is experienced by each individual in very different ways. Culture shock is a crisis of identity. Although symptoms may be similar across experiences, no two people are alike enough to make culture shock curable by way of cookbook methods. It might even be argued that such prescriptive models and 
curves are dangerous for when sojourners experience something which is not accounted for in the model, as is inevitable, it is likely that their trauma will intensify.

In addition to the failings of predeparture orientations briefly discussed above, I see as a crucial flaw in predeparture orientations the extremely narrow focus on language as is mentioned in Chapter IV and the absence of attention to linguistic identity. The discussion of language in which I participated prior to spending a year abroad led me to believe that my knowledge of German would allay any difficulties I might otherwise have anticipated. I could speak the language so I thought I should not have any trouble sorting out for myself any other, non-linguistic, problems that arose. This was of course not the case. Perhaps cross-cultural trainers need to widen their focus to include a more multi-disciplinary approach. Students would certainly benefit by being introduced to notions from sociolinguistics, social anthropology, intercultural communication, and psychology in addition to language instruction. Some cross-cultural trainers (Weaver, 1986; La Brack, 1986) have already begun integrating these other areas into their orientations; others would do well to follow suit.

A very important point made by both Weaver and La Brack is that the focus of cross-cultural training must be shifted from "home-culture-as-familiar" and "foreign-cultureas-new-and-exciting" (La Brack, 1986). Traditionally predeparture orientation has focused on the culture about to be entered and has briefed potential sojourners on all that will seem new and peculiar in an attempt to ward off any element of surprise or shock. Little if any attention was paid to the culture that sojourners were leaving and to the relationship sojourners had with that culture (LaBrack, 1986; Weaver, 1986). La Brack points to the findings of reentry shock which "suggest that the problems encountered in returning can be as substantial and disorienting as initial culture shock" (p. 224). This will certainly be the case if students leave home unaware of the culture they bring with them. Upon returning to their culture-devoid home, they may be very shocked to find that there IS a culture. Indeed 
La Brack's (1986) students report feeling more American after having spent time abroad "but not in a nationalistic sense. They report simply realizing the extent to which their ideas, values and emotional reactions are preconditioned by being raised in a specific nation with English as its primary language" (p. 234).

Weaver's (1986) reasons for shifting the focus of predeparture orientation to include a look at the home culture are different but are related. He feels that drawing attention to the culture of which students are a part will sensitize them to the depth to which that culture effects them. This is especially important in the case of U.S. American students who often "fail to understand their own mainstream culture and tend to view themselves as somewhat cultureless people" (Weaver, 1986, p. 137). This view leads to ethnocentrism which is probably how U.S. Americans perpetuate the reputation abroad that they do not have any culture. A predeparture orientation which looks first at the culture of the sojourners and later at the culture to be visited would serve a dual purpose, especially in the case of U.S. American students. The students would go into their new culture armed with the knowledge that they have a culture and with a clear understanding of how it effects them. Additionally, they would be excited to learn about the new culture and how it would effect them.

\section{PROJECT FOR FURTHER RESEARCH}

As I first began researching the idea that the language identity plays a significant role in the experience of culture shock, I devised a plan which would enable me to explore, with the help of a group of exchange students, the provocative ideas I was forming (see Appendix). This plan was submitted in the form of a research proposal to Fulbright. I hoped to be funded by that organization to further investigate what I was then referring to as language ego. My proposal was not approved and subsequent efforts to find monies proved fruitless. For the time being I have had to limit my thesis project to library research. 
Despite the fact that my proposal was rejected, the Fulbright committee on campus showed animated interest in my pursuing the project. Their support and my determination to further investigate language identity make me confident that I will apply again for funding which will enable me to put my plan into action. The reader will certainly note that my ideas about linguistic identity and the role it and language play in the experience of a new culture have evolved considerably since the initial inception of this plan. These developments in no way effect the legitimacy of the approach or its potential contribution to the understanding of culture shock. Slight modifications would enable me to test whether or not introduction to the notion of linguistic identity prior to departure would, in fact, lessen the trauma of the culture shock experience for this particular group of students.

I hope that I will be able to pursue this research project at a later date for I believe the results of such a project would prove the significance of the linguistic identity in the experience of culture shock. In the meantime, I encourage other researchers to pursue the issues raised in this thesis down avenues of their own choosing. One important research project will entail conducting a study such as is outlined in the Appendix with students who come from other countries to the United States for a year of study. Little research is being done on the adaptation of foreigners in their U.S. American sojourns and the field would benefit from the findings of such a study. Certainly there are more scientific ways to explore the issues I have addressed. That task I will leave to the scientists though, for while I understand the value of approaching language from a purely scientific standpoint, I do not believe that the essence of language can be understood by way of scientific exploration. Language is the powerful tool with which human beings make love and war, build families and cities, and destroy the same. Language is an integral part of our existence and should be recognized as such. Sand indicates in the passage which appears at the head of Chapter IV that language can be dangerous. When one begins to understand the force of language it is awe-inspiring. This force can be just as creative as it can be dangerous though, and it is 
to this creative end that language educators must strive to bring their students for only by learning to speak one anothers' languages and by learning to interact with one another in each others' cultures will the people of this world learn to live peacefully. 


\section{REFERENCES}

Adler, P.S. (1975). The transitional experience: an alternative view of culture shock. Journal of humanistic psychology, 14(14), 13-23.

Adler, P.S. (1977). Beyond cultural identity: reflections upon cultural and multicultural man. In Brislin, R.W. (Ed.). Cultural learning: concepts, applications and research. Honolulu: University Press of Hawaii, pp. 24-41.

Adler, P.S. (1987). Culture shock and the cross-cultural learning experience. In Luce, L.F. and Smith E.C. (Eds.) Toward Internationalism, (2nd Ed.). Cambridge, MA: Newbury House Publishers, (pp. 24-35).

Asante, M.K. and Barnes, A. (1989). Demystification of the intercultural communication encounter. In Asante, M.K. and Gudykunst, W.B. (eds.). Handbook of intercultural communication. Newbury Park, CA: Sage Publication, Inc.

Bachman, L.F. (1990). Fundamental considerations in language testing. Oxford: Oxford University Press.

Barna, L. (1983). The stress factor in intercultural relations. In Landis, D. and Brislin, R. (Eds.) Handbook of intercultural training, Vol. II. Elmsford, N.Y.: Pergamon Press, Inc., pp. 19-49.

Baumeister, R.F. (1986). Identity: cultural change and the struggle for self. New York: Oxford University Press.

Bennett, J. (1977). Transition shock: putting culture shock in perspective. In International and Intercultural Communication Annual, !V, pp. 45-51.

Berger, C. and Calabrese, R. (1975). Some explorations in initial interaction and beyond: toward a developmental theory of interpersonal communicaton. Human Communication Research, (1), 99-111.

Bernstein, B. (1964). Aspects of language learning in the genesis of the social process. In Hymes, D. (Ed.). Language in culture and society. New York: Harper \& Row Publishers, pp. 251-263.

Brewer, M. and Campbell, D. (1976). Ethnocentrism and intergroup attitudes. New York: Wiley.

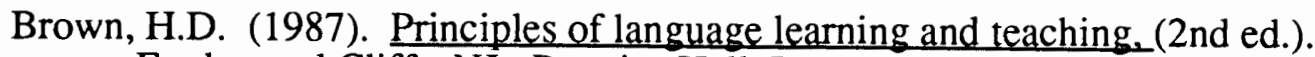
Englewood Cliffs, NJ: Prentice Hall, Inc. 
Byram, M. (1989). Cultural studies in foreign language education. Clevedon, Avon: Multilingual Matters Ltd.

Clark, B.L. and Wiedenhaupt, S. (1992). On blocking and unblocking Sonja: a case study in two voices. In The journal of the conference on college composition and communication, 43 (1), pp. 55-74.

Collier, M.J. and Thomas, M. (1988). Cultural identity: an interpretive perspective. In Kim, Y.Y. and Gudykunst, W.B. (Eds.) Theories in intercultural communication. Newbury Park, CA: Sage Publications, Inc.

Dabrowski, K. (1964). Theory of positive disintegation. In Aronson, J. (Ed.), Positive Disintegration. Boston: Little, Brown \& Company, pp. 1-31.

David, K. (1971). Culture shock and the development of self-awareness. Journal of Contemporary Psychotherapy, 4 (11), 44-48.

DeVos, G., Marsella, A.J., Hsu, F.L.K. (1985). Introduction: Approaches to culture and self. In Marsella, A.J., DeVos,G., and Hsu, F.L.K.. (Eds). Culture and Self: Asian and Western Perspectives. New York: Tavistock Publications, pp. 2-23.

Draguns, J.G. (1976). On culture shock, biculturality, and cultural complexity. Based on remarks at the symposium on culture shock as a social and clinical problem, American Psychological Association, Washington, D.C.

Foster, G.M. (1971) Culture shock. In Traditional cultures and the impact of technological change. New York: Harper \& Row, pp. 187-194.

Furnham, A. (1988). The adjustment of sojourners. In Kim, Y.Y. and Gudykunst, W.B. (Eds.) Cross-Cultural Adaptation. Newbury Park, CA: Sage Publications, Inc., pp. 42-61.

Furnham, A. and Bochner, S. (1986). Culture shock: psychological reactons to unfamiliar environments. New York: Methuen \& Co..

Geertz, C. (1988). Works and lives: the anthropologist as author. Stanford: Stanford University Press.

Geisler, C. (1992). Exploring academic literacy: an experiment in composing. In Conference on college composition and communication. 43 (1), pp. 39-54.

Goldsmith, D. (1992). Ethnography and Uncertainty Reduction Theory: Contrasting Approaches to Cross-cultural Communicaton Theory. Paper presented at Ethnography of Communication Conference, Portland, Oregon. August, 1992.

Giles, $\mathrm{H}$ and Powesland, P. (1975). Speech style and social evaluation. London: Academic Press.

Goodenough, W.H. (1964). Cultural anthropology and linguistics. In Hymes, D. (Ed.). Language in culture and society. New York: Harper \& Row, Publishers, pp. 3639. 
Green, G.M. (1989). Pragmatics and natural language understanding. Hillsdale, N.J.: Lawrence Erlbaum Associates, Publishers.

Gudykunst, W. and Ting-Toomey, S. (1988). Culture and Interpersonal Communication. Newbury Park, CA: Sage Publications, Inc.

Gudykunst, W.B., Kim, Y.Y., and Chua, E. (1984). Communicating with strangers. Reading, MA: Addison-Wesley Publishing Company.

Guiora, A.Z. (1981). Language, personality and culture or the Whorfian-hypothesis revisited. In M. Hines and W. Rutherford (Eds.), On TESOL '81 (pp. 169-177). Washington, D.C.: Teachers of English to Speakers of Other Languages.

Guiora, A.Z., Brannon, R.C., and Dull, C.Y. (1972). Empathy and second language learning. Language Learning, 22, 111-130.

Gullahorn, J.T. and Gullahorn, J.E. (1963). An extension of the U-curve hypothesis. Journal of Social issues, 19 (3), pp. 33-47.

Gumperz, J.J. and Cook-Gumperz, J. (1982). Introduction: language and the communication of social identity. In Gumperz, J.J. (Ed.) Language and social identity. Cambridge: Cambridge University Press, (pp. 1-21).

Guthrie, G.M. (1975). A behavioral analysis of culture learning. In Brislin, R.(Ed.) Cross-cultural perspectives on learning. New York: Halsted Press, pp. 97-115.

Habermas, J. (1973). Legitimation Crisis. Boston, MA: Beacon Press.

Hall, E.T. (1981a). Beyond Culture. New York: Doubleday.

Hall, E.T. (1981b). The Silent Language. New York: Doubleday.

Harris Jr., J.G. (1976). Culture shock: the experience and the behavior in diverse settings. Presented as part of a symposium entitled Culture Shock: A Clinical and Social Phenomenon, American Psychological Association, Washington, D.C.

Hawkins, B. (1986). Teaching children to read in a second language. In Celce-Murcia, M. (Ed.) Teaching English as a second or foreign language, 2nd Ed. Boston: Heinle \& Heinle, Publishers, pp. 169-184.

Hymes, D.H. (1972). On communicative competence. In Pride, J.B. and Homes, J. (Eds.) Sociolinguistics: selected readings. Harmondsworth, England: Penguin Books.

Kim, Y.Y. (1989). Intercultural Adaptation. In Asante, M.K. and Gudykunst, W.B. (Eds.) Handbook of international and intercultural communication. Newbury Park, CA: Sage Publications, Inc. pp. 275-294.

Kohls, R.L. (1984). Survival kit for overseas living. Yarmouth, ME: Intercultural Press, Inc. 
Krashen, S. (1981). Second language acquisition and second language learning. Oxford: Pergamon Press.

La Brack, B. (1986). Orientation as process: the integration of pre- and postexperiences learning. In Paige, M.R. (Ed.) Cross-cultural orientation: new conceptualizations and applications. Lanham, MD: University Press of America, Inc., pp. 223-246.

Levinson, D.J. Darrow, C.N., Klein, E.B., Levinson, M.H., and McKee, B. (1978). The seasons of a man's life. New York: Ballantine.

Nattinger, J. (1993). Lecture notes from Sociolinguistics. Portland State University, Winter 1993.

Nisbett, R., Caputo, C., Legant, P., and Marecek, J. (1973). Behavior as seen by the actor and as seen by the observer. Journal of Personality and Social Psychology (27), 2, pp. 154-164.

Oberg, K. (1960). Culture shock: adjustment to new cultural environments. Practical Anthropology, $7,177-182$.

Olmsted, D.W. (1961). Social groups, roles and leadership: an introduction to the concepts. East Lansing, MI: Michigan State University.

Paige, R.M. (1986). Introduction to new dimensions in the theory and practice of crosscultural orientation. In Paige, M.R. (Ed.) Cross-cultural orientation: new conceptualizations and applications. Lanham, MD: University Press of America, Inc., pp. 1-25.

Richards, J.C. and Rodgers, T.S. (1986). Approaches and methods in language teaching: a description and analysis. Cambridge: Cambridge University Press.

Samovar, L.A. and Porter, R.E. (1991). Language and culture: sounds and actions. In Samovar, L.A. and Porter, R.E. Communication between cultures. Belmont, CA: Wadsworth Publishing Co., pp. 145-169.

Sand, George. (1978). Indiana. Chicago: Academy Chicago, Publishers.

Sapir, E. (1921). Speech as a personality trait. In Mandelbaum, D.G. (Ed.) Selected writings of Edward Sapir in language, culture and personality. Berkeley: University of California Press, pp.

Sapir, E. (1929). The status of linguistics as a science. In Mandelbaum, D.G. (Ed.) Selected writings of Edward Sapir in language, culture and personality. Berkeley: University of California Press, pp.

Scarcella, R and Krashen, S. (1980). Research in second language acquisition: selected papers of the Los Angelos second language research forum. Rowley, MA: Newbury House Publishers, Inc.

Sommers, N. (1992). Between the drafts. In College composition and communication, $\underline{43}$ (1), pp. 23-31. 
Tajfel, H. (1981). Social categorization, social identity and social comparison. In Human groups and social categories: studies in social psychology. Cambridge: Cambridge University Press, pp. 254-267.

Tajfel, H. (1982). Social identity and intergroup relations. Cambridge: Cambridge University Press.

Tajfel, H. and Turner, J.C. (1992). The social identity theory of intergroup behavior. In Gudykunst, W.B. and Kim, Y.Y. (Eds.) Readings on communicating with strangers. New York: McGraw Hill, pp. 112-119

Ting-Toomey, S. (1992). Identity and interpersonal bonding. In Gudykunst, W.B. and Kim, Y.Y. (Eds.) Readings on communicating with strangers. New York: McGraw Hill, pp. 119-132.

Wardhaugh, R. (1992). An introduction to sociolinguistics, (2nd ed.). Oxford: Blackwell.

Weaver, G.R. (1986). Understanding and coping with cross-cultural adjustment stress. In Paige, M.R. (Ed.) Cross-cultural orientation: new conceptualizations and applications. Lanham, MD: University Press of America, Inc., pp. 111-145.

Winter, G. (1986). German-American student exchange: adaptation problems and opportunities for personal growth. In Paige, M.R. (Ed.) Cross-cultural orientation: new conceptualizations and applications. Lanham, MD: University Press of America, Inc., pp. 311- 339. 


\section{APPENDIX}

\section{A PROPOSAL FOR FUTURE RESEARCH}

As I began to investigate Guiora's language ego, I decided to attempt a major research project which would enable me to ascertain what sort of a relationship language and culture share. At my disposal was the perfect subject group -- an exchange program through which students from Oregon study for one year in Germany. I had been a participant of this program so I was able to vouch for its success. My idea was to travel to Germany with this group of 35-40 students and to track their transition experiences over the course of a year. I would interview them prior to their departure to determine what their motivations were and what sort of exposure they had had to other cultures. I also intended to establish an understanding of what their expectations were of their trip and what fears they had. A follow-up interview, conducted in small group format in conjunction with their pre-departure orientation, would have enabled me to determine what their understanding of culture shock was before they departed and how they anticipated reacting to or coping with such an experience.

My chief objective in accompanying those students to Germany was to establish whether or not an understanding of language ego would ease the difficulty of grappling with culture shock. I did not plan to introduce the students to my ideas early on; rather, I had planned to have them draw their own conclusions guided by my research. Having completed this much of the research project, though, I believe it would be more valuable to set up a test group which would be briefed on linguistic identity prior to its departure to determine if their adaptation was any smoother than that of the control group. 
I anticipated being on hand at their post-departure orientation, which lasts one month, establishing myself as a familiar, trustworthy confidante who would be attractive to the students because of my experience on the same exchange program. During this on-site orientation I had not planned to pursue my research actively; rather I hoped to use the intimacy of the situation to establish a camaraderie with the students. I would have discussed my research with them, but I would not have betrayed my hypothesis. Rather, I would have tried, in the course of the year, to establish whether or not the students, with a little prodding from me, might not reach my conclusions on their own.

Once the students had departed to the sites where they were to spend their year of study abroad, I would have begun to collect information from them on what they saw as being their transition experiences. Some students would agree to keep dialogue journals which I would collect and read on a regular basis. I planned to respond in written form to whatever questions arose either with suggestions or with additional questions which might have enabled the students to draw their own conclusions.

At three junctures in the program, at the post-departure orientation, immediately following the Christmas vacation, and just prior to the students' return home, I planned to conduct small group, informal interviews with the students at the different university sites. My plan for these interviews was two-fold. I hoped to provided them with a forum like the one my friends on the exchange program established, in which they could discuss whatever complications they were experiencing with one another. My fear is that many students do not discuss their problems with one another so they never realize that they are not alone. I hoped to allay alienation. I also planned to videotape these informal interviews so as to accomplish my second goal. As I discussed my research plan with friends, the suggestion was raised that I compile video footage which might then be used in future orientation programs. The idea was that students who were 
contemplating a trip abroad might listen more carefully to students who were in the midst of such a trip than they might to students who had returned already or to actors who were merely reading script lines. This idea is very appealing to me and I think it could be very successfully integrated into pre-departure orientation programs.

Once the students had returned home, I considered the option of keeping in touch with some of them for a few months to get their in hindsight reactions to their trip. This would probably prove to be a formidable task, but since reverse culture shock, or re-entry shock, is the current topic of interest in culture shock study, it is certainly worth pursuing.

I will be moving to Germany in the fall of 1993 . Although I do not currently have the funds necessary for such a research project, I will continue to apply for grants which will enable me to conduct what I support as being an extremely viable contribution to culture shock research and to the field of linguistics. 